\title{
Light absorption by pollution, dust, and biomass burning aerosols: a global model study and evaluation with AERONET measurements
}

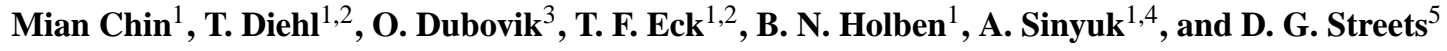 \\ ${ }^{1}$ Laboratory for Atmospheres, NASA Goddard Space Flight Center, Greenbelt, MD, USA \\ ${ }^{2}$ University of Maryland at Baltimore County, Baltimore, MD, USA \\ ${ }^{3}$ Laboratoire d'Optique Atmospherique, Universite de Lille 1/CNRS, Villeneuve d'Ascq, Lille, France \\ ${ }^{4}$ Science Systems and Applications, Inc., Lanham, MD, USA \\ ${ }^{5}$ Argonne National Laboratory, Argonne, IL, USA
}

Received: 31 March 2009 - Accepted: 20 August 2009 - Published: 2 September 2009

\begin{abstract}
Atmospheric aerosol distributions from 2000 to 2007 are simulated with the Goddard Chemistry Aerosol Radiation and Transport (GOCART) model to attribute light absorption by aerosol to its composition and sources from pollution, dust, and biomass burning. The 8-year, global averaged total aerosol optical depth $(\tau)$, absorption optical depth $\left(\tau_{a}\right)$, and single scattering albedo $(\omega)$ at $550 \mathrm{~nm}$ are estimated at $0.14,0.0086$, and 0.95 , respectively, with sulfate making the largest fraction of $\tau$ (37\%), followed by dust $(30 \%)$, sea salt (16\%), organic matter (OM) (13\%), and black carbon (BC) (4\%). BC and dust account for $43 \%$ and $53 \%$ of $\tau_{a}$, respectively. From a model experiment with "tagged" sources, natural aerosols are estimated to be $58 \%$ of $\tau$ and $53 \%$ of $\tau_{a}$, with pollution and biomass burning aerosols to share the rest. Comparing with data from the surface sunphotometer network AERONET, the model tends to reproduce much better the AERONET direct measured data of $\tau$ and the Ångström exponent $(\alpha)$ than its retrieved quantities of $\omega$ and $\tau_{a}$. Relatively small in its systematic bias of $\tau$ for pollution and dust regions, the model tends to underestimate $\tau$ for biomass burning aerosols by $30-40 \%$. The modeled $\alpha$ is $0.2-0.3$ too low (particle too large) for pollution and dust aerosols but $0.2-0.3$ too high (particle too small) for the biomass burning aerosols, indicating errors in particle size distributions in the model. Still, the model estimated $\omega$ is lower in dust regions and shows a much stronger wavelength dependence for biomass burning aerosols but a weaker one for pollution aerosols than those quantities from AERONET. These comparisons necessitate model improvements on aerosol size distributions, the refractive indices of
\end{abstract}

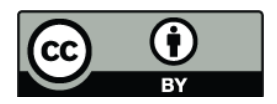

Correspondence to: Mian Chin (mian.chin@nasa.gov) dust and black carbon aerosols, and biomass burning emissions in order to better quantify the aerosol absorption in the atmosphere.

Keywords. Atmospheric composition and structure (Aerosols and particles)

\section{Introduction}

Aerosol absorption in the atmosphere plays important roles in climate change. Aerosol radiative forcing is determined not only by the total amount of aerosol in the atmosphere but also by the abundance of the absorbing components (e.g., Hansen et al., 1997; Ackerman et al., 2000). Light-absorbing particles warm the atmosphere that offset the cooling effects by non-absorbing aerosols such as sulfate (IPCC, 2007). The degree of aerosol-cloud-precipitation interaction critically depends on the absorbing aerosols, since they could change cloud fraction (Kaufman and Koren, 2006), cloud cover and cloud albedo (Hansen et al., 1997), atmospheric circulation, and precipitation pattern and duration (Menon et al., 2002; Kim et al., 2006; Lau et al., 2006). Furthermore, the absorption in the ultraviolet and shortwave visible solar spectral wavelengths can affect the atmospheric chemistry by altering the photodissociation rates for key oxidants (Dickerson et al., 1997; Martin et al., 2003; Bian et al., 2003).

Absorption of solar radiation in urban and biomass burning environments is attributed mainly to the presence of strong light absorbing carbonaceous aerosols, largely black carbon (BC), whereas in arid and semiarid regions and downwind mineral dust is a main absorbing species. The absorbing ability of aerosol species is determined by the imaginary part of the complex refractive index, which for $\mathrm{BC}$ is of two

Published by Copernicus Publications on behalf of the European Geosciences Union. 
orders of magnitude higher than for dust (e.g., Kinne et al., 2003). However, the atmospheric mass loading of dust is also about two orders of magnitude higher than that of BC, making the total absorption in the solar spectrum comparable to BC.

Despite its importance, determining the effects of aerosol absorption remains difficult. Large uncertainty in the optical properties of absorbing aerosols proves to be a major factor. In most cases, the measurements of aerosol optical properties either are limited to particular source regions (e.g. Saharan dust) or confined to a small span of wavelength range (e.g., mid-visible), and, in some cases, have not been updated for decades. Yet, more complications occur when the particles are internally mixed with several aerosol components as the optical properties of such a mixture could be quite different from externally mixed particles (e.g., Jacobson, 2000; Stier et al., 2006; Schwarz et al., 2008). Another difficulty in quantifying the aerosol absorption arises from the large variability of aerosols. Unlike the long-lived greenhouse gases, such as carbon dioxide and methane, which have lifetimes from tens to hundreds of years, aerosols have short lifetimes ranging from less than one day to one or two weeks. The short lifetime combined with highly variable and often episodic absorbing aerosol sources, such as wind-blown dust and biomass burning, result in highly inhomogeneous distributions of absorbing aerosols in space and time.

Numerous observations of aerosol absorption have been conducted in several field experiments (see Bergstrom et al., 2007, for a summary), from surface based networks (e.g. Dubovik et al., 2002; Delene et al., 2002), and from satellite retrievals (Torres et al., 2005). Among them, the most comprehensive and probably the most accurate dataset is that from the ground-based sunphotometer network, the Aerosol Robotic Network (AERONET), which has been measuring total aerosol optical depth $(\tau)$ and retrieving aerosol single scattering albedo $(\omega)$ and aerosol absorption optical depth $\left(\tau_{a}\right)$ at multiple wavelengths for more than a decade worldwide. Nonetheless, while the AERONET data have been commonly used for satellite and model validations and for a wide range of aerosol research, they in fact lack vertical information, have limited coverage over ocean, and can only retrieve absorption information with sufficient accuracy in relatively high aerosol loading environments.

Keeping in mind both the necessities and difficulties involved in defining aerosol absorption, we present here global model simulated aerosol absorption with the Goddard Chemistry Aerosol Radiation and Transport (GOCART) model from 2000 to 2007 . Our purpose is to quantify the aerosol absorption in the atmosphere as a function of sources, regions, and spectral dependence for climate studies. We first describe the model components and how the absorption is calculated (Sect. 2), then we evaluate the model simulated key aerosol parameters of $\tau, \tau_{a}, \omega$, and the Ångström Exponent ( $\alpha$, indication of aerosol size) with the AERONET measurements/retrievals at different world regions (Sect. 3).
We then present the global distributions of these parameters and attribute them to the aerosol composition and to the origin of pollution, dust, and natural sources (Sect. 4), followed by conclusions on major findings (Sect. 5).

\section{Model simulation of aerosol components and optical depth}

The GOCART model uses assimilated meteorological fields from the Goddard Earth Observing System Data Assimilation System (GEOS DAS). In this study, the version 4 of GEOS DAS is used to drive an off-line simulation of global aerosols at a resolution of $2.5^{\circ}$ longitude by $2^{\circ}$ latitude and 30 vertical layers. Atmospheric processes include emission, chemistry, boundary layer mixing, advection, convection, dry and wet depositions, and hygroscopic growth of aerosol particles. Details of the GOCART model are described in our previous publications (Chin et al., 2000, 2002, 2004, 2007; Ginoux et al., 2001, 2004); a brief summary and recent updates are given below.

\subsection{Anthropogenic and natural emissions}

The aerosol simulation in GOCART from 2000 to 2007 includes major aerosol types of sulfate, dust, BC, organic carbon (OC), and sea salt, and the precursor gas species of $\mathrm{SO}_{2}$ and dimethylsulfide (DMS). The model accounts for time-varying emissions from anthropogenic, biomass burning, biogenic, and volcanic sources, wind-blown dust, and sea salt. The annual anthropogenic emissions of $\mathrm{SO}_{2}, \mathrm{BC}$, and OC between 2000 and 2006 (Streets et al., 2009) are used and they are estimated by considering more than 100 combinations of combustor technology, particle collection device, fuel type, and fuel use (Streets et al., 2004; Bond et al., 2004). Other anthropogenic emissions include the aircraft and ship emissions, which are interpolated or extrapolated from the available database (Eyring et al., 2005, for international ship emission; Mortlock et al., 1998, for aircraft emissions from the Atmospheric Effects of Aviation Project database). Biomass burning emissions of $\mathrm{SO}_{2}, \mathrm{BC}$, and $\mathrm{OC}$ are calculated using the dry mass burned dataset from the Global Fire Emission Dataset version 2 (GFED v2) (van der Werf et al., 2003, 2006; Randerson et al., 2007) and the emission factors from Chin et al. (2004), which for BC and OC are $1 \mathrm{~g} \mathrm{~kg}^{-1}$ and $8 \mathrm{~g} \mathrm{~kg}^{-1}$, respectively, that can be $40-$ $100 \%$ higher than most commonly used values (Andreae and Merlet, 2001) but are within the observed range (see Chin et al., 2002). Volcanic emissions of $\mathrm{SO}_{2}$ from sporadically erupting volcanoes are constructed from a combination of the Global Volcanism Program database (Siebert and Simkin, 2002; http://www.volcano.si.edu/world/), satellite $\mathrm{SO}_{2}$ data from the Total Ozone Mapping Spectrometer (TOMS) (Carn et al., 2003) and the Ozone Monitoring Instrument (OMI) (Krotkov et al., 2006; Carn et al., 2008), and in some cases 

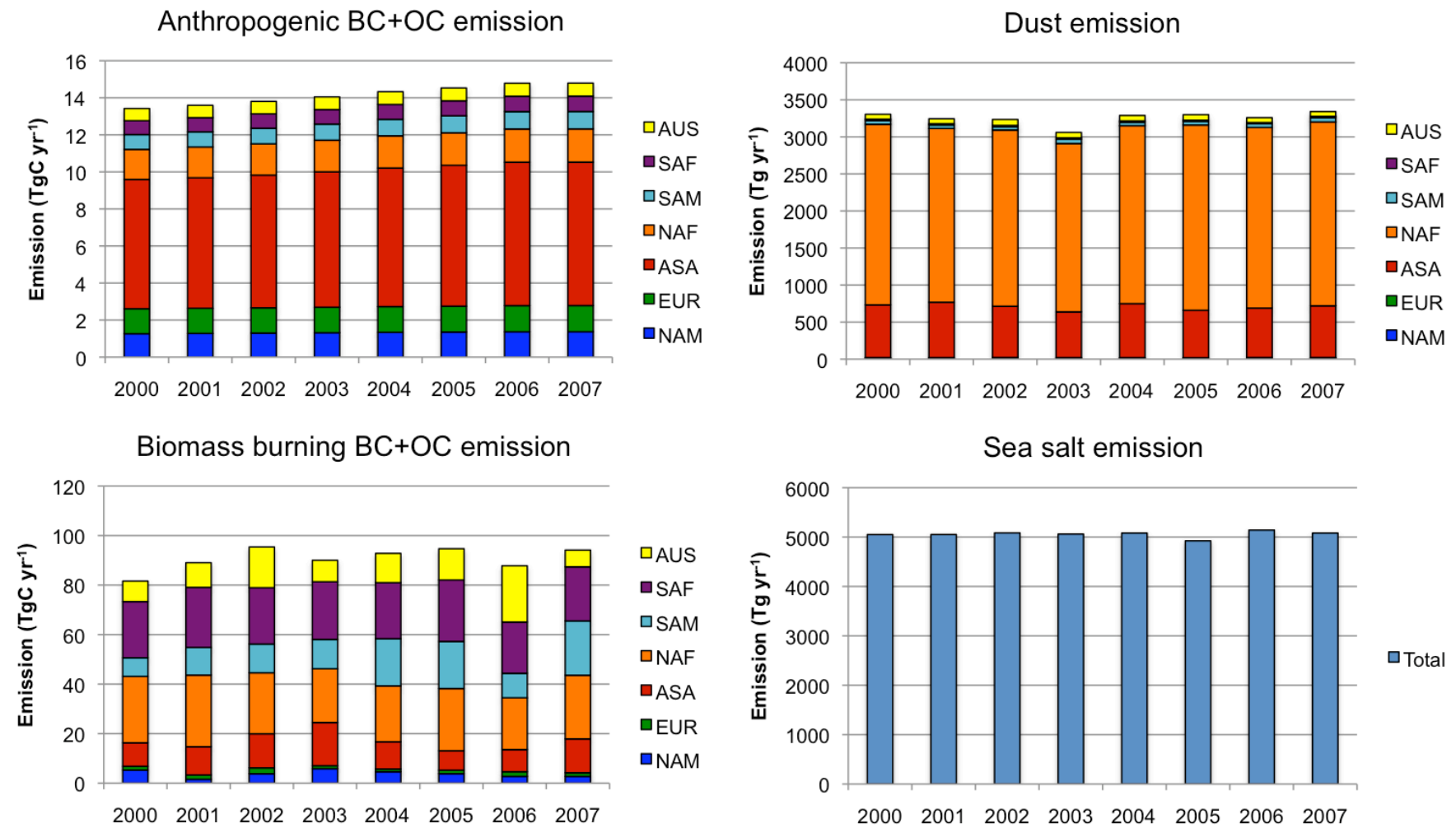

Anthropogenic sulfur emission
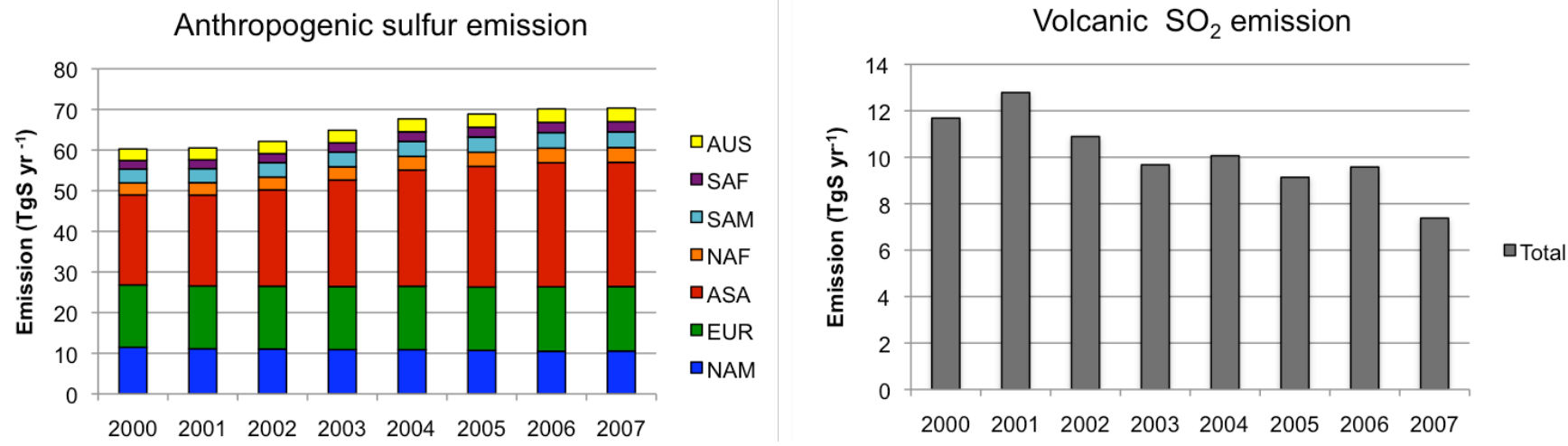

Fig. 1. Emissions of aerosols and precursor gases from their major sources and source regions from 2000 to 2007, annual total amount. NAM $=$ North America, EUR = Europe, ASA = Asia, NAF = northern Africa and Middle East, SAM = South America, SAF = southern Africa, AUS $=$ Australia/New Zealand and countries in the tropical South Pacific. See Fig. 4 for region domains.

from reported measurements near the volcanoes (Diehl et al., 2009). Emissions of $\mathrm{SO}_{2}$ from continuously degassing volcanoes are from Andres and Kasgnoc (1998) and are assumed to be constant. The magnitude of volcanic eruption and volcanic $\mathrm{SO}_{2}$ index (Bluth et al., 1997) are used to estimate the injection height, plume thickness, and the emitted $\mathrm{SO}_{2}$ amount if not available from observations (Chin et al., 2000; Diehl et al., 2009). Dust and sea salt emissions with particle radius from 0.01 to $10 \mu \mathrm{m}$ are calculated instantaneously in the model as a function of surface winds and other conditions (Ginoux et al., 2001; Gong et al., 2003).
Figure 1 shows the annual emission from 2000 to 2007 of carbonaceous aerosols (BC and OC) from anthropogenic and biomass burning sources, $\mathrm{SO}_{2}$ from anthropogenic and volcanic sources, dust, and sea salt. The anthropogenic, biomass burning, and dust emissions are divided into 7 world regions, roughly within North America (NAM), Europe (EUR), Asia (ASA), northern Africa and Middle East (NAF), South America (SAM), southern Africa (SAF), Australia/New Zealand/tropical Western Pacific countries (AUS) (domains shown in Fig. 4). With the 2007 anthropogenic emission not yet available, this study uses the 2006 anthropogenic emission in the 2007 simulations. The 

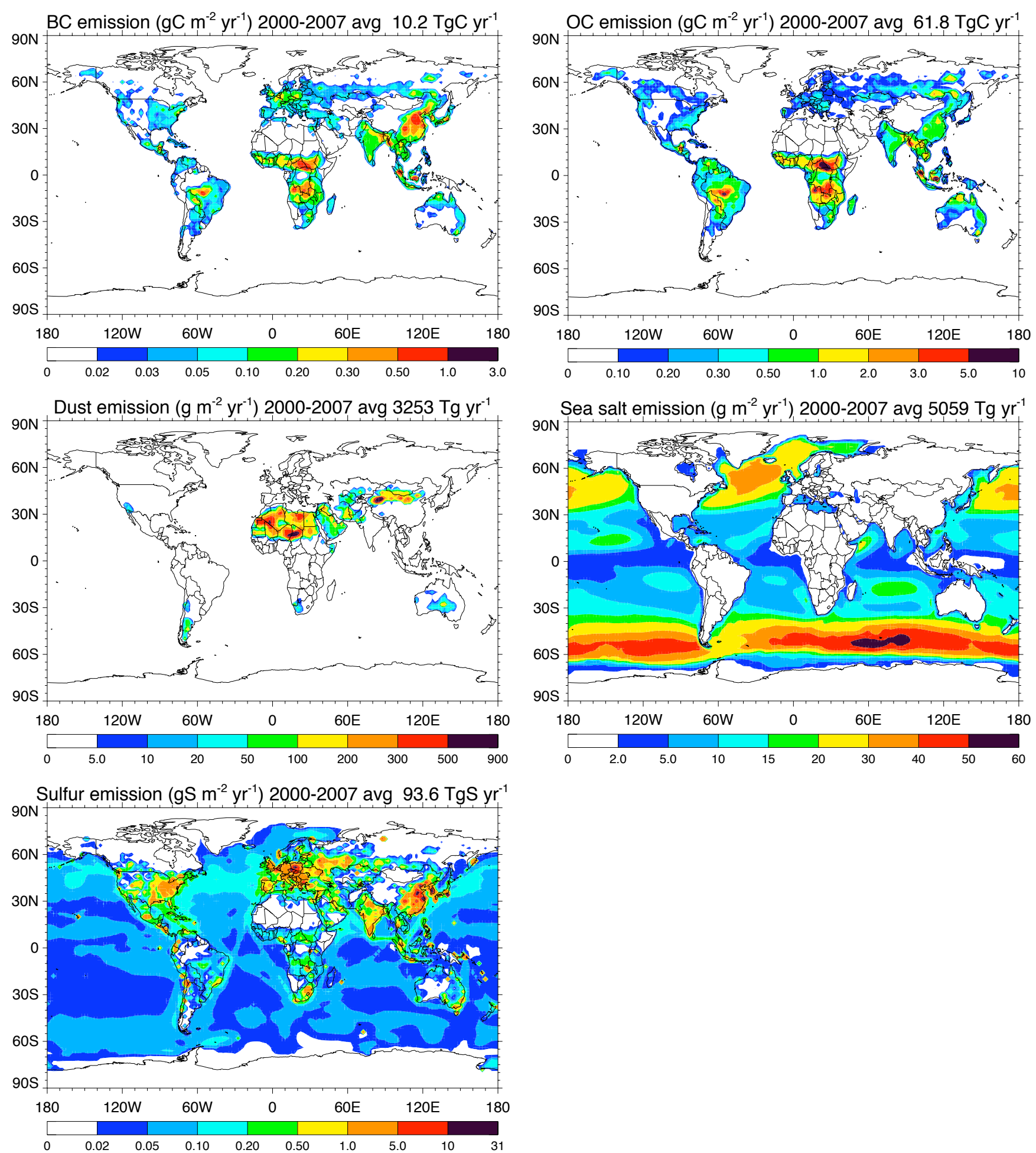

Fig. 2. 8-year (2000-2007) averaged emission rates of BC, OC, dust, sea salt, and sulfur from all (including anthropogenic, biogenic, volcanic, biomass burning, and oceanic) sources. Emission of sulfur includes gaseous phase $\mathrm{SO}_{2}$ and DMS and particulate sulfate emissions.

anthropogenic carbonaceous aerosol emissions have a small, but steady increase from 2000 to 2006 for all regions, and the anthropogenic emission of $\mathrm{SO}_{2}$ has also increased in most re- gions especially in Asia, but decreased in North America and kept nearly constant in Europe. The change in anthropogenic emission is a combined result of economic development and 
Table 1. Aerosol and precursor emissions averaged from 2000 to 2007.

\begin{tabular}{lrr}
\hline Species/source & $\begin{array}{r}\text { 8-year avg. Emission } \\
\left(\mathrm{Tg} \mathrm{M} \mathrm{yr}^{-1}\right)^{\mathrm{a}}\end{array}$ & $\begin{array}{r}\text { Range } \\
\left(\mathrm{Tg} \mathrm{M} \mathrm{yr}^{-1}\right)^{\mathrm{a}}\end{array}$ \\
\hline BC & 10.2 & \\
Pollution & 5.2 & $4.8-5.5$ \\
Biomass burning & 5.0 & $4.5-5.3$ \\
OC & 61.8 & \\
Pollution & 8.9 & $8.5-9.2$ \\
Biomass burning & 40.2 & $36.1-42.3$ \\
Biogenic & 12.7 & - \\
Sulfurc & 93.6 & \\
Pollution & 65.5 & $60.2-70.2$ \\
Biomass burning & 2.8 & $2.9-3.0$ \\
Volcanic & 10.2 & $7.4-12.8$ \\
DMS & 15.1 & $14.8-15.4$ \\
Dust & 3250 & $3060-3340$ \\
Sea salt & 5060 & $4920-5140$ \\
\hline
\end{tabular}

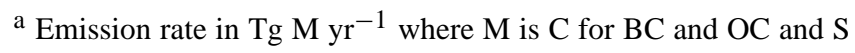
for sulfur emissions.

b Biogenic OC source is the conversion of terpene emitted from vegetation to organic aerosol. We use the same terpene emission from Guenther et al. (1997) for every year.

${ }^{c}$ Sulfur emission including $\mathrm{SO}_{2}$ emissions from pollution, biomass burning, and volcanic sources, a small fraction (3\%) of sulfate from anthropogenic sources, and DMS from the ocean.

fuel-use efficiency in those regions. Biomass burning emissions, on the other hand, have large year-to-year variations in different regions where the differences can be more than a factor of 3 among the years, except in Africa (northern and southern) where the interannual variations are relatively small. The interannual variability of dust and sea-salt is small (within 3\%), although regionally the variations are larger. Compared to other sources, volcanic emissions are more variable. The 8-year averaged emission rates of $\mathrm{BC}$, $\mathrm{OC}$, dust, sea salt, and sulfur (including gaseous phase $\mathrm{SO}_{2}$ from anthropogenic, volcanic, biomass burning sources and DMS from ocean and particulate sulfate from anthropogenic sources) are shown in Fig. 2 as global maps; the mean value and the range of annual emissions are listed in Table 1.

\subsection{Aerosol optical properties}

The optical properties of sulfate, BC, OC, dust, and sea salt are based on the Optical Properties of Aerosols and Clouds (OPAC) (also known as Global Aerosol Dataset, Köpke et al., 1997; Hess et al., 1998); the size distributions and refractive indices used in our calculations are described in Chin et al. (2002) and listed here in Table 2. All aerosols except dust have different degree of hygroscopic growth under ambient conditions, which is parameterized as a function of relative humidity (Chin et al., 2002). The aerosol optical depth, $\tau$, is
Table 2. Particle density $(\rho)$, modal and effective radii $\left(r_{m}\right.$ and $\left.r_{e}\right)$, geometric standard deviation $\left(\sigma_{g}\right)$ in lognormal size distribution, and refractive indices at $550 \mathrm{~nm}$ for dry aerosols.

\begin{tabular}{lrrrrr}
\hline Species & $\begin{array}{r}\rho \\
\left(\mathrm{g} \mathrm{cm}^{-3}\right)\end{array}$ & $\begin{array}{r}r_{m} \\
(\mu \mathrm{m})\end{array}$ & $\begin{array}{r}r_{e} \\
(\mu \mathrm{m})\end{array}$ & $\begin{array}{r}\sigma_{g} \\
(\mu \mathrm{m})\end{array}$ & $\begin{array}{r}\text { Refractive index } \\
\text { at } 550 \mathrm{~nm}\end{array}$ \\
\hline BC $^{\mathrm{a}}$ & 1.0 & 0.0118 & 0.039 & 2.00 & $1.75-0.44 i$ \\
OC $^{\mathrm{a}}$ & 1.8 & 0.0212 & 0.087 & 2.20 & $1.53-0.006 i$ \\
Sulfate $^{\mathrm{a}}$ & 1.7 & 0.0695 & 0.156 & 2.03 & $1.43-10^{-8} i$ \\
Dust & 2.6 & 0.0421 & 0.14 & 2.00 & $1.53-0.0055 i$ \\
& 2.6 & 0.0722 & 0.24 & 2.00 & $1.53-0.0055 i$ \\
& 2.6 & 0.1354 & 0.45 & 2.00 & $1.53-0.0055 i$ \\
& 2.6 & 0.2407 & 0.80 & 2.00 & $1.53-0.0055 i$ \\
& 2.6 & 0.4212 & 1.40 & 2.00 & $1.53-0.0055 i$ \\
& 2.6 & 0.7220 & 2.40 & 2.00 & $1.53-0.0055 i$ \\
Sea salt & 2.6 & 1.3540 & 4.50 & 2.00 & $1.53-0.0055 i$ \\
& 2.6 & 2.4070 & 8.00 & 2.00 & $1.53-0.0055 i$ \\
& 2.2 & 0.228 & 0.80 & 2.03 & $1.50-10^{-8} i$ \\
& 2.2 & 1.64 & 5.73 & 2.03 & $1.50-10^{-8} i$ \\
\hline
\end{tabular}

a Assuming maximum radius at $0.5 \mu \mathrm{m}$.

calculated as $\tau_{i}=\beta_{i} M_{d}$ where the subscripts $i=$ null for total extinction optical depth, $a$ for absorption and $s$ for scattering optical depth, respectively; $\beta$ is the mass extinction (or absorption, or scattering) cross-section $\left(\mathrm{m}^{2} \mathrm{~g}^{-1}\right)$, also known as mass extinction (absorption, scattering) efficiency, and $M_{d}$ is the dry aerosol mass load in $\mathrm{g} \mathrm{m}^{-2}$ (see Chin et al., 2002, for more details). The property of aerosol absorption is often expressed with single scattering albedo $\omega$, which is $\tau_{s} / \tau$ : the lower the $\omega$, the more the absorption. Figure 3 illustrates the spectral-dependent quantities of $\beta$ and $\omega$ of sulfate, $\mathrm{BC}, \mathrm{OC}$, sea salt, and dust at two different sizes. In the atmosphere, $\tau$ and $\omega$ depends on the absolute and relative abundance of different types of aerosols, respectively, as well as their hygroscopic growth. All aerosols are treated as external mixture in this study due to the difficulties in quantifying the mixing state and the resulting optical properties in our current capacity.

Figure 3 shows that the specific extinction $\beta$ decreases with the increase of wavelength for sulfate, $\mathrm{BC}$, and $\mathrm{OC}$ from 0.2 to $2 \mu \mathrm{m}$ in wavelength but stays rather constant for coarse mode sea salt and dust. Small particles such as sulfate, BC, and OC are much more efficient in light extinction in the UV to visible wavelength than sea salt and dust ( $\beta$ values for these small particles are 5 to 10 times higher than dust and sea salt in the mid-visible). The major absorbing aerosols in the UV to visible spectral range are dust and BC (right column, Fig. 3). As wavelength increases, BC becomes more absorbing whereas dust becomes less absorbing. Meanwhile, OC also displays some absorbing ability at near UV but the $\omega$ becomes much lower in near IR. For the hydroscopic aerosols, the larger the particle size (because of larger $\mathrm{RH}$ ), the more efficient the total extinction (higher $\beta$ ) but less 

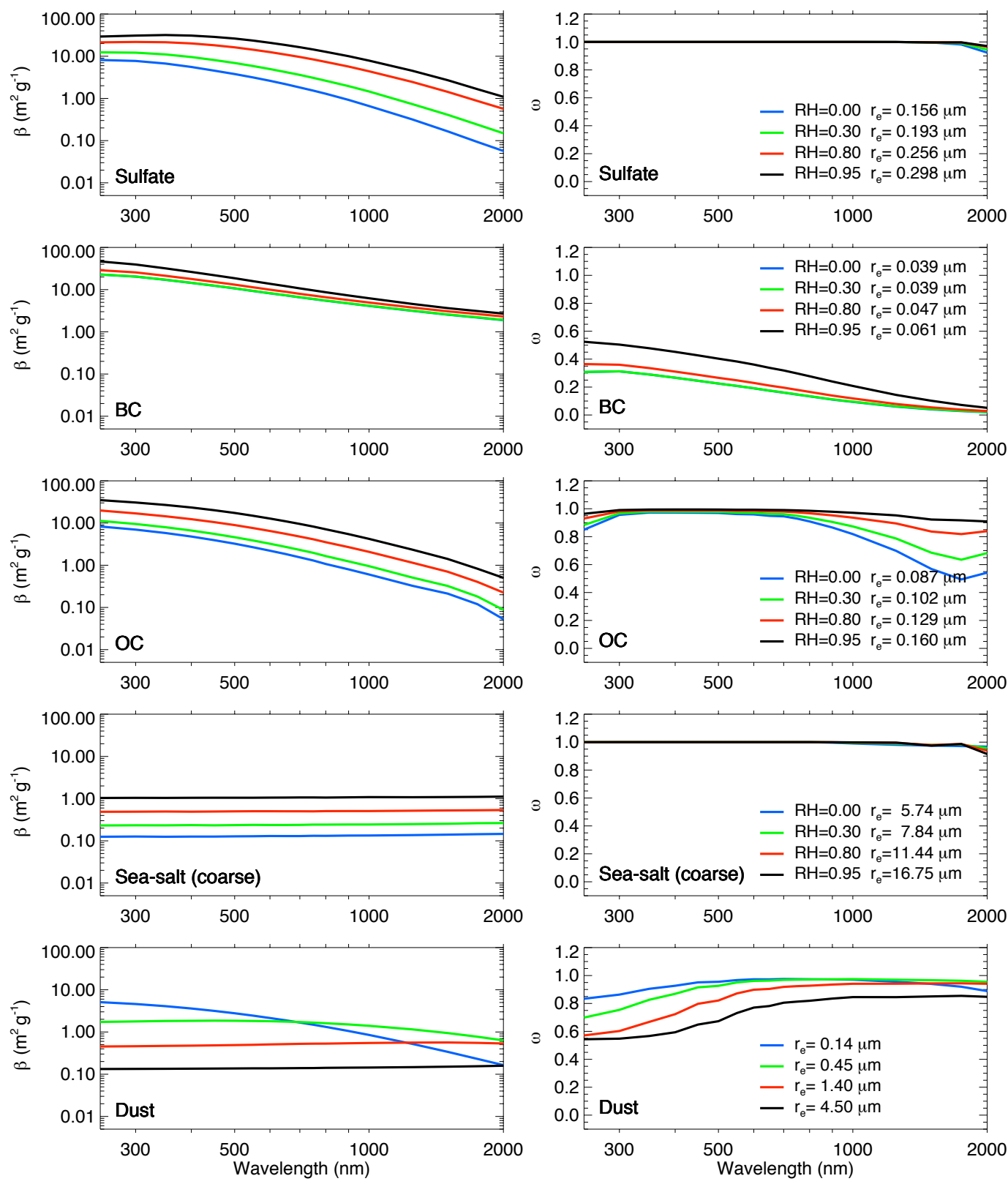

Fig. 3. Mass extinction cross-section (aka mass extinction efficiency) $\beta$ (left column) and single scattering albedo $\omega$ (right column) for sulfate, BC, OC, coarse sea salt, and dust as a function of wavelength from 250 to $2000 \mathrm{~nm}$. Four different sizes of each species are shown with respective effective radius $\left(r_{e}\right)$ at different RH values indicated in the panels in the right column.

absorbing because of higher water fraction in the aerosol particle; on the other hand, for dust aerosols which we consider as non-hygroscopic, the larger the particle size, the less efficient they are in total extinction albeit more absorbing.

The aerosol optical properties listed in Table 2 and Fig. 3 however are subject to possible large uncertainties. Some recent studies have shown different values than what we used here, such as BC and dust refractive indices or single scattering albedo, but currently the OPAC dataset is the most comprehensive one in covering the optical properties in a wide spectral range from UV to infrared for different aerosol species. We first evaluate the model simulated $\tau$ and $\tau_{a}$ using the properties in Table 2 with the AERONET data, and the possible errors will be discussed in Sect. 3.4. 


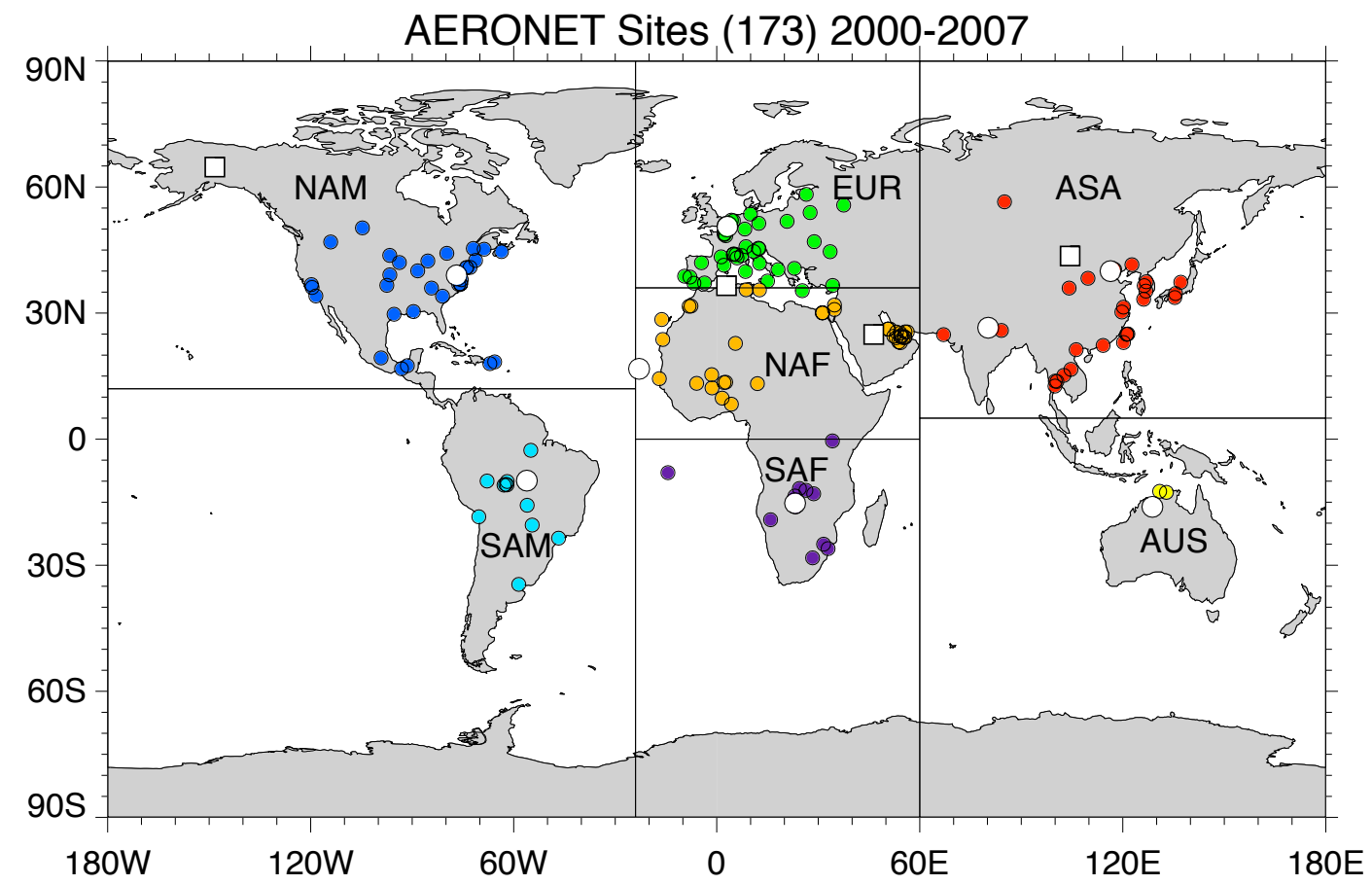

Fig. 4. AERONET site locations where simultaneous $\tau$ and $\tau_{a}$ data are available for at least 20 days during 2000 to 2007 (total 173 sites). Eight sites in white circles are selected for detailed analysis shown in Fig. 5 (GSFC, USA, $40.0^{\circ} \mathrm{N}, 76.8^{\circ} \mathrm{W}$; Lille, France, $51.6^{\circ} \mathrm{N}$, $3.1^{\circ} \mathrm{E}$; Kanpur, India, $26.5^{\circ} \mathrm{N}, 80.2^{\circ} \mathrm{E}$; Beijing, China, 40.0 $\mathrm{N}, 116.4^{\circ} \mathrm{E}$; Cape Verde, Sal Island, $16.7^{\circ} \mathrm{N}, 22.9^{\circ} \mathrm{W}$; Alta Floresta, Brazil, $9.9^{\circ} \mathrm{S}, 56.1^{\circ} \mathrm{W}$; Mongu, Zambia, $15.3^{\circ} \mathrm{S}, 21.2^{\circ} \mathrm{E}$; Lake Argyle, Australia, $\left.16.1^{\circ} \mathrm{S}, 128.8^{\circ} \mathrm{E}\right)$. These sites together with another four sites in white squares (Bonanza Creek, USA, $64.7^{\circ} \mathrm{N}, 148.3^{\circ} \mathrm{W}$; Blida, Algeria, 36.5 $\mathrm{N}, 2.9^{\circ} \mathrm{E}$; Solar Village, Saudi Arabia, $24.9^{\circ} \mathrm{N}, 46.4^{\circ} \mathrm{E}$; Dalanzadgad, Mongolia, $43.6^{\circ} \mathrm{N}, 104.4^{\circ} \mathrm{E}$ ) are used for the spectral dependence analysis of $\omega$ in Fig. 7.

\section{Comparisons with AERONET data in world regions}

\subsection{AERONET}

The AERONET program is a worldwide ground-based sun photometer network (Holben et al., 1998), which started in the early 1990s with more than a dozen sites and has since grown to include over 200 sites (http://aeronet.gsfc. nasa.gov). The automatic tracking sun and sky scanning radiometers make direct measurements of $\tau$ at 340, 380, 440, $500,675,870,940$, and $1020 \mathrm{~nm}$ (nominal wavelengths) during daytime, with an accuracy of $\sim 0.01-0.02$. In addition, sky radiance measurements at $440,675,870$, and $1020 \mathrm{~nm}$ (nominal wavelengths) in conjunction with the direct sun measured $\tau$ at these same wavelengths were used to retrieve aerosol size distributions and refractive indices, providing the spectral dependence of $\omega$ and $\tau_{a}$ (e.g. Dubovik and King, 2000; Dubovik et al., 2002, 2006). In this study, we use the version 2 AERONET $\tau, \tau_{a}$, and $\omega$ from 2000 to 2007, which is improved from the version 1 retrieved products ( $\tau_{a}$ and $\omega$ ) by accounting for the mixtures of spherical and nonspherical particle shapes and the better defined surface reflectance (Dubovik et al., 2006; Sinyuk et al., 2007; Eck et al., 2008). Because of the low sensitivity to the absorption when aerosol loading is low, $\tau_{a}$ and, in particular, $\omega$ are re- trieved with sufficiently high accuracy only when the total $\tau$ at $440 \mathrm{~nm}$ is equal or higher than 0.4 and solar zenith angle is 50 degree or higher (Dubovik et al., 2000, 2002). Therefore the retrieved products, $\tau_{a}$ and $\omega$, are much less available than the direct measurements of $\tau$ and limited in an environment with relatively high aerosol loading.

Aerosol particle sizes are commonly inferred from the spectral dependence of $\tau$, expressed as the Ångström Exponent or $\alpha: \alpha=-\log \left(\tau_{1} / \tau_{2}\right) / \log \left(\lambda_{1} / \lambda_{2}\right)$, where $\tau_{1}$ and $\tau_{2}$ are aerosol optical depth at wavelengths $\lambda_{1}$ and $\lambda_{2}$, respectively. Smaller particles have stronger wavelength dependence (as illustrated in Fig. 3) thus larger $\alpha$. Since the dependence of $\log (\tau)$ on $\log (\lambda)$ is not strictly linear (e.g. Eck et al., 1999; also see Fig. 3), the estimates of $\alpha$ may change with different selected wavelength ranges. Here we use the $\alpha$ determined from $\tau$ at 440 and $870 \mathrm{~nm}$.

Figure 4 shows the location of the 173 AERONET sites that have at least 20 days of simultaneous data of both $\tau$ and $\tau_{a}$ at four wavelengths of $440,675,870$, and $1020 \mathrm{~nm}$ during the 2000-2007 period. We further mark these sites with different colors according to their geographical locations in the 7 world regions described in Sect. 2.1. These regions in general have distinct characteristics: In NAM and EUR aerosols are mostly from pollutions sources, in NAF mostly dust, and 

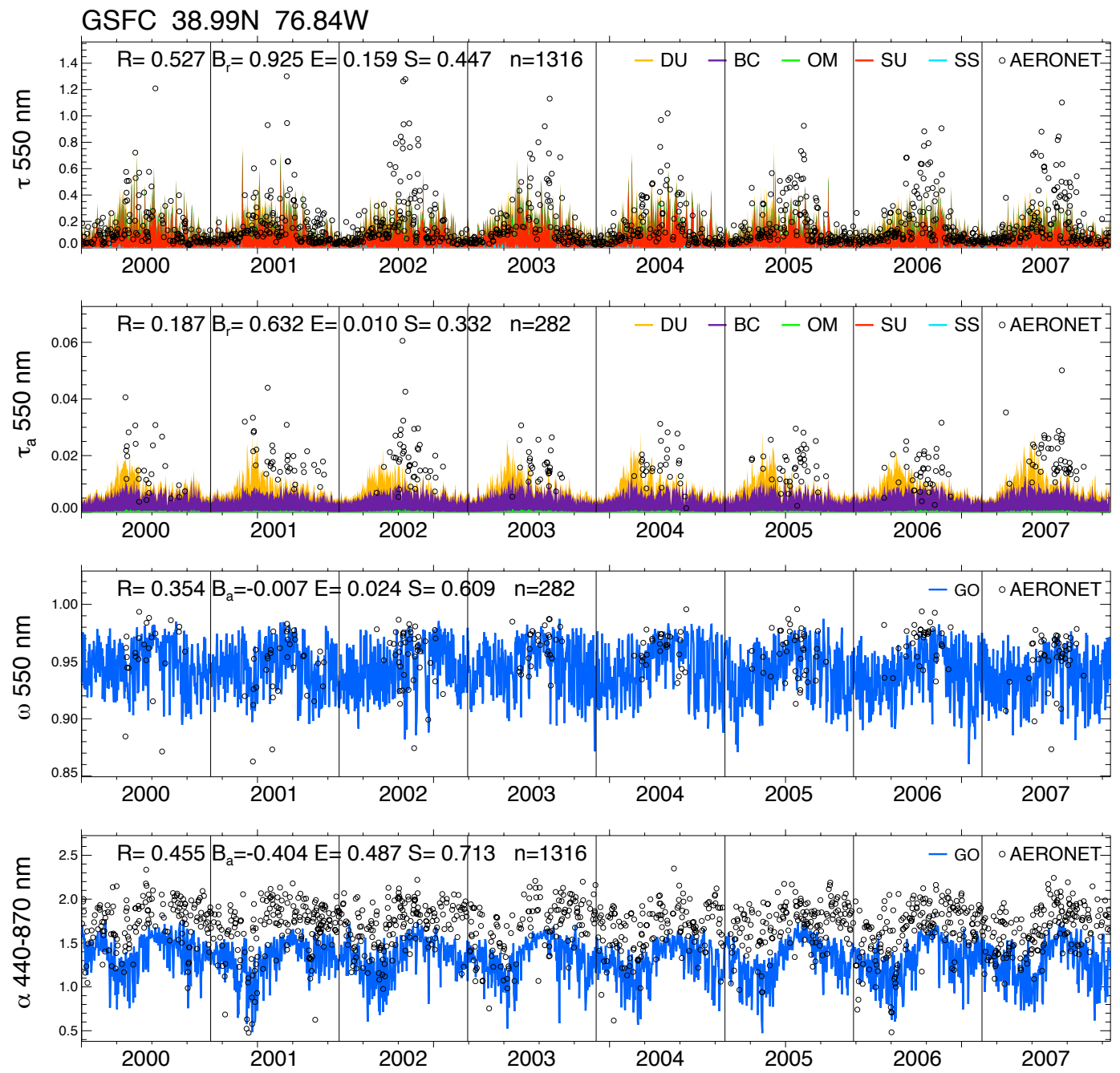

Fig. 5a. Daily aerosol optical depth ( $\tau$, 1st panel), absorption optical depth $\left(\tau_{a}\right.$, 2nd panel), single scattering albedo ( $\omega$, 3rd panel) at $550 \mathrm{~nm}$ and Ångström exponent derived from $\tau$ at $440-870 \mathrm{~nm}(\alpha$, last panel) at Goddard Space Flight Center (GSFC) in eastern USA. In the first two panels, GOCART aerosol components accumulated to total amount are shown in shaded color with DU=dust, BC=black carbon, $\mathrm{OM}=$ organic matter, $\mathrm{SU}=$ sulfate, and $\mathrm{SS}=$ sea salt. In the last two panels, model values are shown blue line with GO=GOCART. On each panel, $R=$ correlation coefficient, $B=$ bias with $B_{r}$ in first two panels as relative mean bias, i.e. $\Sigma(\mathrm{GOCART} i) / \Sigma(\mathrm{AERONET} i)$ and $B_{a}$ in the last two panels as absolute bias, i.e. $\Sigma($ GOCART $i-A E R O N E T i) / n$ ( $n=$ total number of observations), $E=$ root-mean-square error, and $S=$ skill score. See text (Sect. 3.2) for calculation of $S$.

in SAM and SAF mostly biomass burning aerosols. Aerosol composition is more diverse in ASA: dust in northwestern and northern central China, heavy pollution in eastern China and India, and pollution and biomass burning in southern part of ASA. Although there is also a variety of aerosol types in AUS region, such as biomass burning aerosols in northern Australia and Southeast Asia and dust in central and western Australia, it is the biomass burning aerosol that is the major component in the three AERONET sites located in the northern Australia (Fig. 4).

\subsection{Daily variations of AOD and optical properties in different aerosol regimes}

Comparisons between AERONET and GOCART are shown in Fig. 5 on daily variations of $\tau, \tau_{a}, \omega(550 \mathrm{~nm})$ and $\alpha$ $(440-870 \mathrm{~nm})$ at 8 selected sites from the 7 regions. The AERONET $\tau$ at $550 \mathrm{~nm}$ is interpolated from the measurements at 440 and $675 \mathrm{~nm}$, using the logarithmic relationships between $\tau$ and $\lambda$ (see Sect. 3.1). To convert organic carbon to organic aerosols or organic matter (OM), we multiply the mass of OC by a factor of 1.4 (Malm et al., 1994, 2003) then report the value of OM optical depth thereafter. The aerosol composition from the model is plotted in 

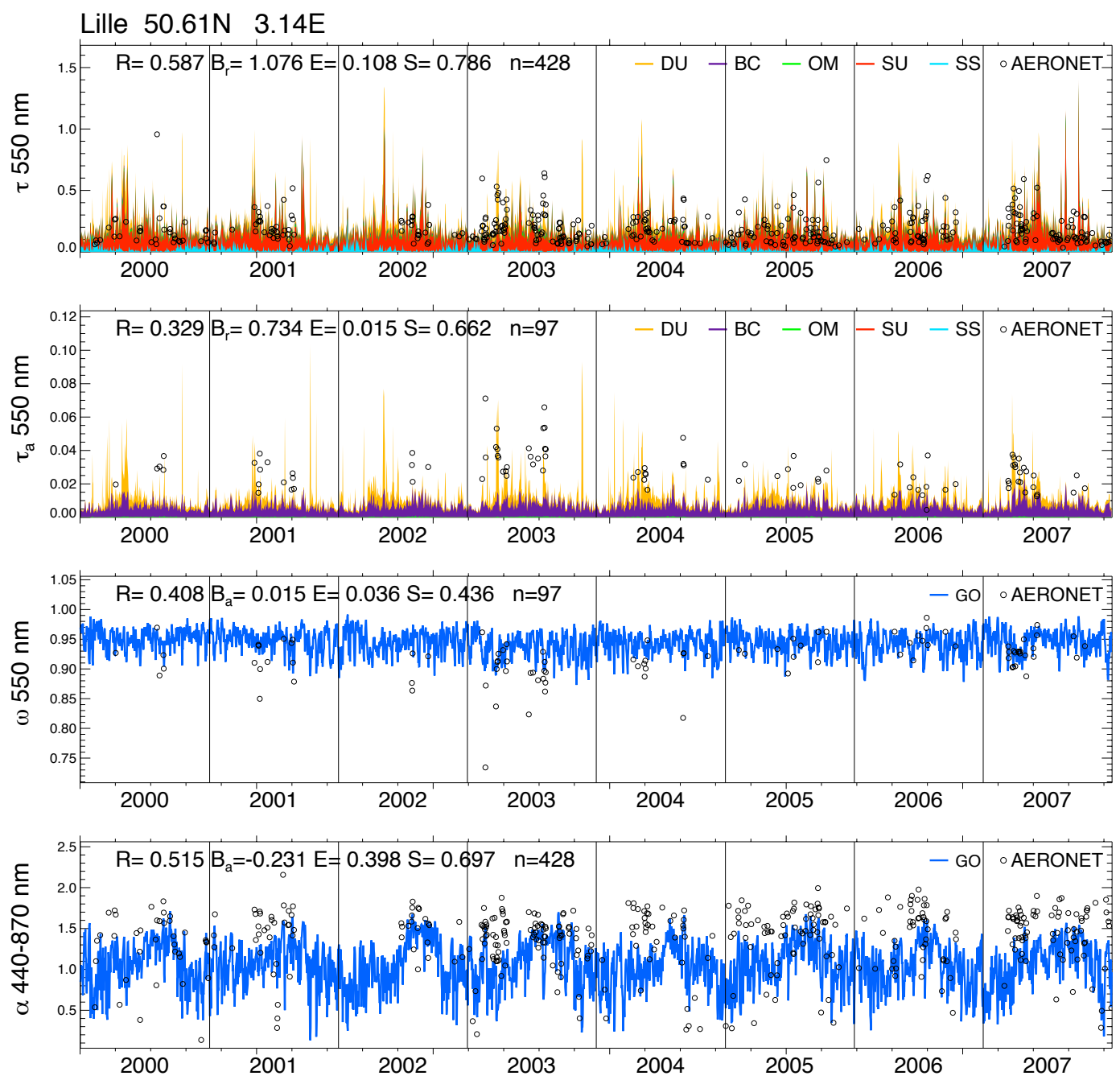

Fig. 5b. Same as Fig. 5a but for Lille, France.

different color shades in Fig. 5a-h. Four statistical parameters that measure the degree of model performance against the AERONET data are also listed on each panel in Fig. 5: correlation coefficient $(R)$, relative or absolute mean bias $\left(B_{r}\right.$ for $\tau$ and $\tau_{a}$ and $B_{a}$ for $\omega$ and $\alpha$, respectively), root-meansquare error $(E)$, and skill score $(S)$ which is calculated as $S=4(1+R) /\left[\left(\sigma_{f}+1 / \sigma_{f}\right)^{2}\left(1+R_{0}\right)\right]$ where $\sigma_{f}$ is the ratio of the standard deviation of model to that of observation and the $R_{0}$ is the maximum attainable $R$ which is set to 1 (Taylor, 2001; see Chin et al., 2003, for more details in using it for model evaluation).

Over the GSFC site in the eastern US (Fig. 5a), the model indicates a predominant presence of sulfate aerosol for all seasons (top rows, Fig. 5a), only perturbed by dust sporadically from the long-range transport. Although $\mathrm{BC}$ only has a very small fraction in total $\tau$, it dominates $\tau_{a}$ at GSFC except in spring when $\tau_{a}$ of long-range transported dust is of similar magnitude. However, the model underestimates both $\tau$ and $\tau_{a}$ in the summer at GSFC. Both model and AERONET re- veal similar seasonal variations of $\omega$ and $\alpha$, with the highest value of both in the summer, meaning an increasing fraction of non-absorbing pollution aerosols (mostly sulfate) and a decreasing in aerosol particle size from winter to summer. Though closely reproducing the seasonal variation of $\alpha$, the modeled values are typically 0.4 lower than the AERONET data (as shown in the $B_{a}$ value on the last panel in Fig. 5a). One might argue that the model may contain too much dust to bring the $\alpha$ down as our previous study on surface aerosol concentrations has shown that the model may have overestimated the fine mode dust at the surface (Chin et al., 2007); however, even if all the aerosols were sulfate, the $\alpha$ would only be about 1.7 (ref. Fig. 3), still lower than the AERONET value near 2.0 in the summer season. We will discuss this in Sect. 3.4.

Sulfate again is the dominant component of $\tau$ in Lille (Fig. 5b) located at the north most part of France near the coast of North Sea. For its proximity to the North Sea, Lille can have a substantial fraction of sea salt aerosols in the 

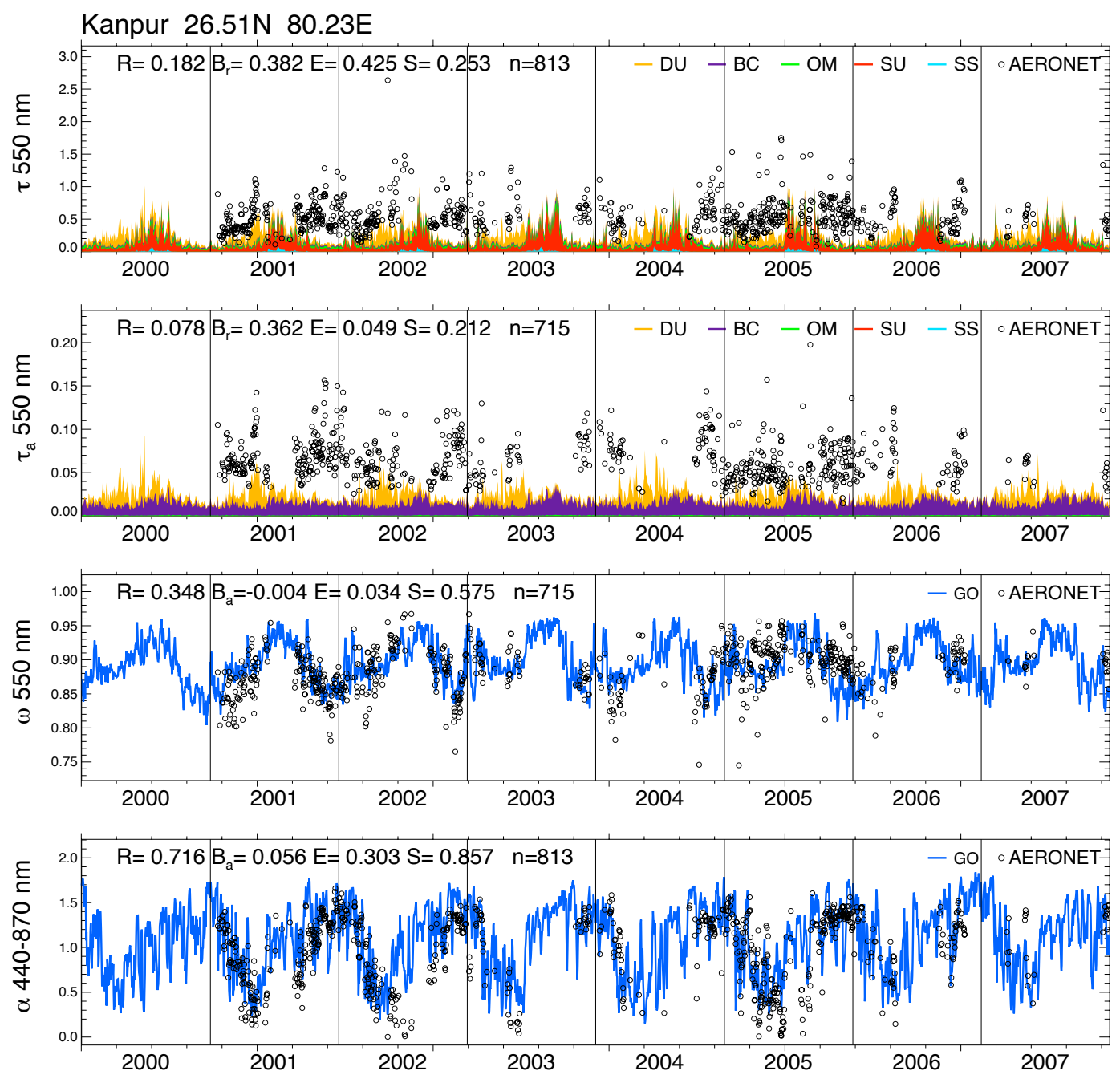

Fig. 5c. Same as Fig. 5a but for Kanpur, India.

winter when the winds are strong. The seasonal variation of aerosol composition is reflected in the change of $\alpha$ (bottom panel, Fig. 5b) which is much lower in the winter than in the summer because of higher fraction of sea salt in the winter. The $\tau$ and $\tau_{a}$ exhibit large day-to-day variations from the model, which is also shown in the AERONET data although the retrieved $\tau_{a}$ are only available for a fraction of the time each year. The modeled $\omega$ stays above 0.87 throughout whereas AERONET occasionally shows very low $\omega(0.72$ to $0.82 ; 3$ rd panel, Fig. 5b). The modeled $\alpha$ is on average about 0.2 lower than the AERONET value for Lille.

The model severely underestimates both $\tau$ and $\tau_{a}$ over Kanpur, India (Fig. 5c, top two panels), with values on average more than $60 \%$ lower than the AERONET data, especially in the winter. Interestingly, the $\omega$ and $\alpha$ from the model agree with the AERONET data in both seasonal variation and magnitude with little bias (Fig. 5c, bottom two panels). Black Carbon is the major absorbing component over Kanpur, but the seasonal variations of $\omega$ and $\alpha$ is regulated by the relative abundance of dust and sulfate as the model suggested, both with significant seasonal changes. The fact that the model has underestimated $\tau$ and $\tau_{a}$ but at the same time well captured the $\omega$ and $\alpha$ implies that the model estimated fractions of each aerosol components are perhaps correct but the magnitudes are not. Considering that dust and pollution come from different locations to Kanpur (dust is mostly transported from the Thar Desert in India/Pakistan in the west, pollution is mostly emitted locally) but have the same magnitude of bias, it is possible that the underestimation of $\tau$ and $\tau_{a}$ by the model is a large-scale phenomenon, probably due to the model resolution and/or the removal processes, not necessarily the wrong emissions.

In Beijing, China (Fig. 5d), both $\tau$ and $\tau_{a}$ are considerably higher than those from other pollution sites discussed previously (Fig. 5a-c), with daily maximum $\tau$ reaching 2.5 and $\tau_{a}$ over 0.2 from the AERONET data. The model again 
Beijing $39.98 \mathrm{~N} 116.38 \mathrm{E}$
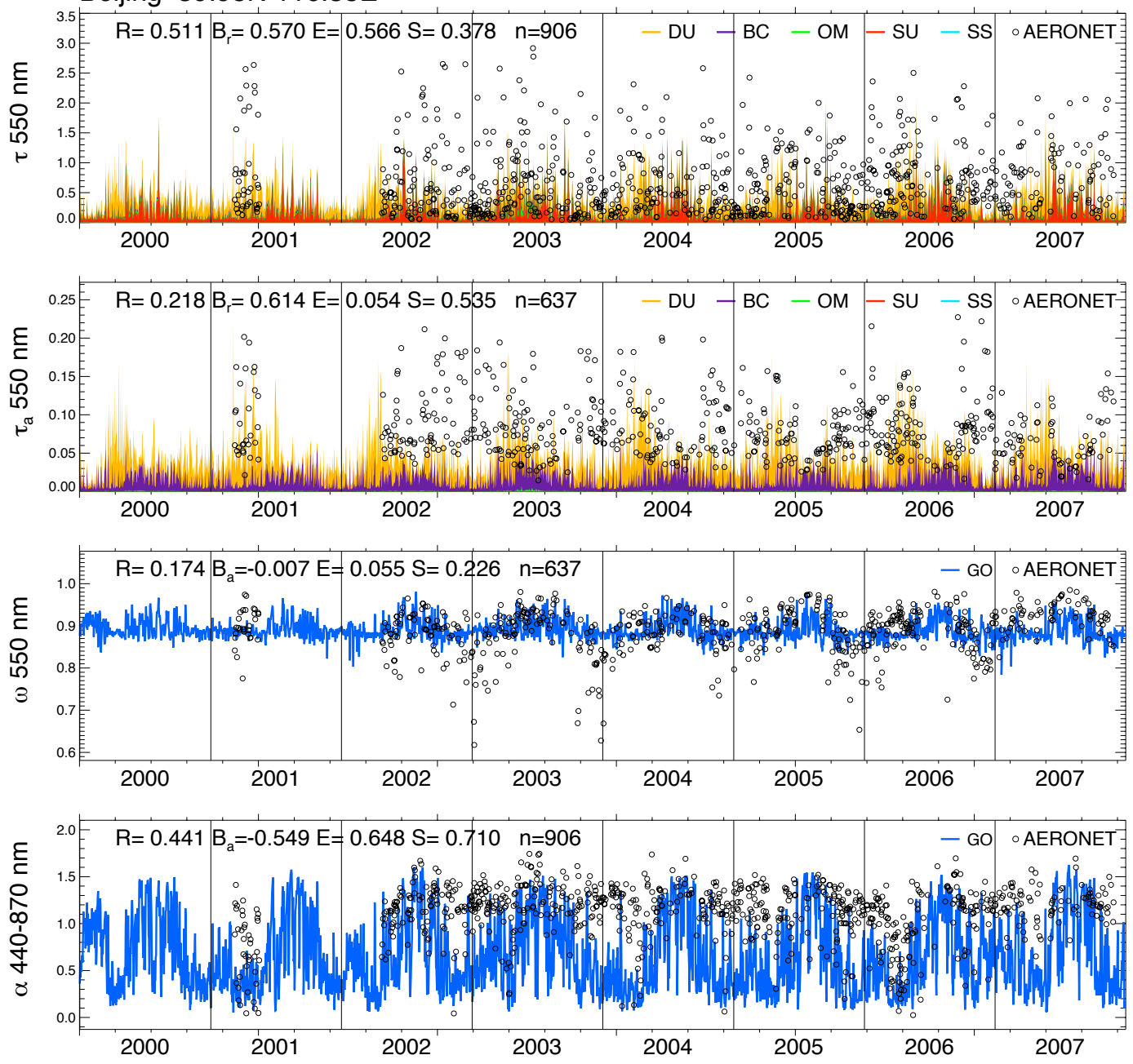

Fig. 5d. Same as Fig. 5a but for Beijing, China.

significantly underestimates (about $40 \%$ on average) the $\tau$ and $\tau_{a}$ over that site (top two panels, Fig. 5d). In addition, AERONET data show weak seasonal variations of $\tau$ whereas the model simulates a much stronger seasonal cycle. Strong dust intrusion events occur regularly in the spring, which are reflected in the low $\alpha$ values in both AERONET and the model (bottom panel, Fig. 5d). However, the modeled pollution level in the winter, most probably from the absorbing aerosols, is too low, causing much higher $\omega$ and much lower $\alpha$ than AERONET. In this case, the emission of primary absorbing carbonaceous aerosols or the secondary organic aerosols formed in the atmosphere from pollution sources may have been significantly underestimated in the model. On the other hand, in situ measurements in Beijing during the wintertime showed that the dust usually account for $\geq 50 \%$ of the total aerosol mass concentrations at the surface (e.g., Duan et al., 2007; Yuan et al., 2008). Therefore, it is possible that the surface and column aerosol composition are quite different in Beijing in the wintertime.
Dust transported from the Sahara desert overwhelms both $\tau$ and $\tau_{a}$ over Cape Verde (Fig. 5e), located right off the west coast of northern Africa, resulting in typical $\alpha$ values below 0.5. In the wintertime, the site is influenced by the Sahel biomass burning, making a sharp increase of $\alpha$ in the winter to above 1 (bottom panel, Fig. 5e). The modeled $\tau$ on average agrees with the AERONET data to within $10 \%$, but the model overestimates $\tau_{a}$ by more than $50 \%$ on average. The difference between AERONET and GOCART in the aerosol absorption is also reflected in the $\omega$ : the modeled $\omega$ is 0.03 to 0.04 lower than that from the AERONET ( 3 rd panel, Fig. 5e). This difference points to the dust optical properties in the model (Table 2), which is likely being too absorbing.

The three Southern Hemispheric sites shown in Fig. 5f to h, Alta Floresta in Brazil (Fig. 5f), Mongu in Zambia (Fig. 5g), and Lake Argyle in Australia (Fig. 5h), are mainly dominated by biomass burning aerosol, with OM being the major aerosol component of $\tau$ and $\mathrm{BC}$ the major component of $\tau_{a}$. Although the seasonality is quite regular, as the 

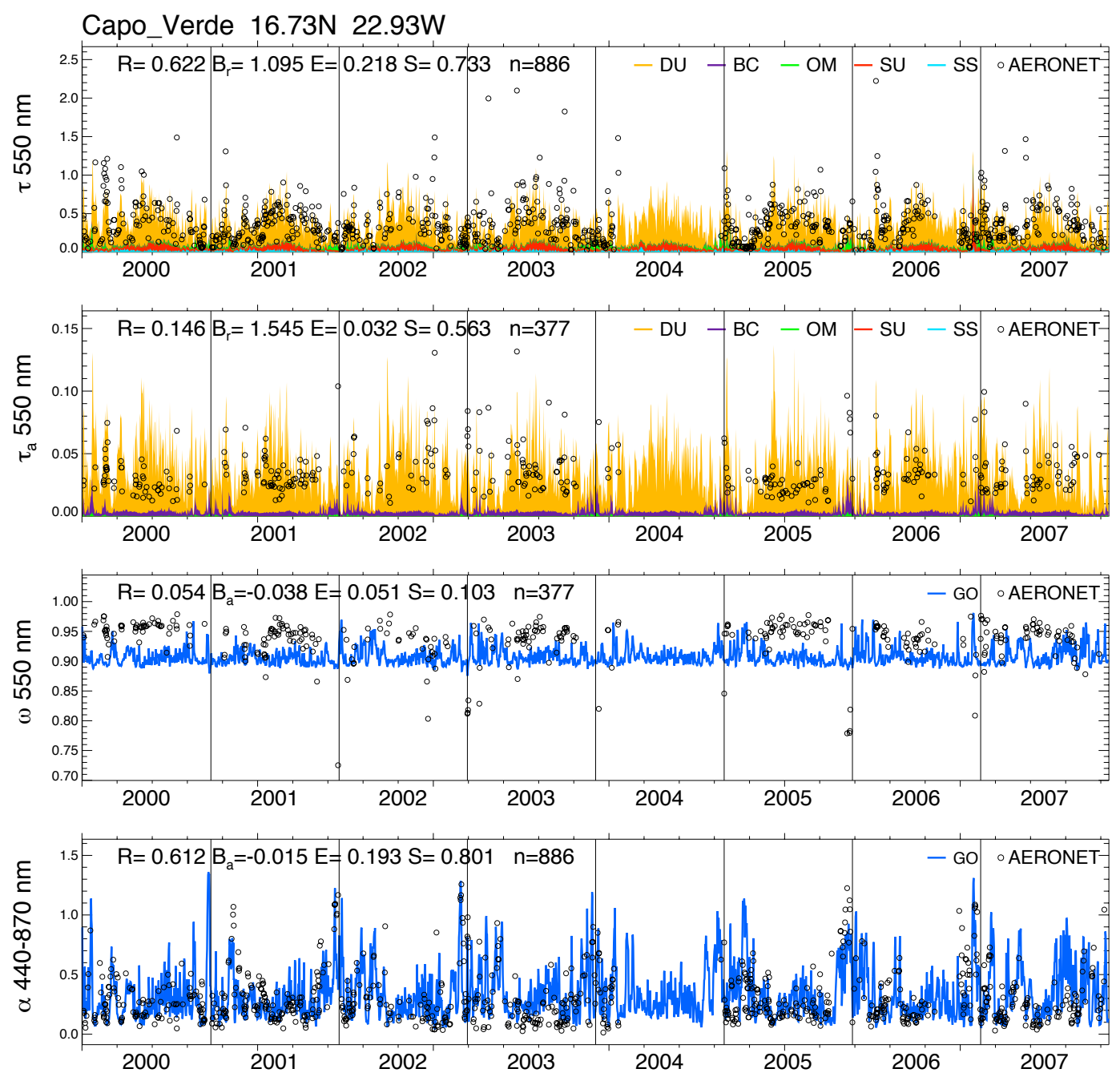

Fig. 5e. Same as Fig. 5a but for Cape Verde, off the west coast of northern Africa.

fire activity peaks in August to September over Alta Floresta and Mongu and a month later over Lake Argyle, there are significant year-to-year variations of the fire intensity. For example, the average $\tau$ in September 2007 in Alta Floresta is twice as high as that in the same month in 2000 from AERONET. At the peak of biomass burning time, the model estimates a similar $\omega$ for all three sites to be 0.82 to 0.85 ; this value appears to be too low for Alta Floresta but too high for Mongu and Lake Argyle as compared to AERONET data. The AERONET data thus suggest that the aerosol released from Mongu and Lake Argyle, mainly from the shrublands and savanna burning, is more absorbing than that released from Alta Floresta that is mainly from broadleaf forest burning. This difference between absorption of biomass burning aerosols in different regions has also been discussed in previous AERONET papers (e.g., Dubovik et al., 2002, Eck et al., 2003, 2009; Reid et al., 2005). The model does not account for the difference in $\mathrm{BC}$ to $\mathrm{OM}$ emission ratios in differ- ent biomass types, which would overestimate the absorption in Alta Floresta but underestimate the absorption in Mongu and Lake Argyle. Another difference between AERONET and GOCART is the particle size; the modeled $\alpha$ values are much larger (or particle sizes are much smaller) than the AERONET data over Alta Floresta in the non-burning period but agree with AERONET in Mongu. Some observations over the Amazon suggested the size of organic particles from the biogenic sources in Amazon can be much larger than that from pollution sources (J. V. Martins, personal communication, 2009), but the model does not make such a distinction.

\subsection{Overall comparisons of $\tau, \tau_{a}, \omega$, and $\alpha$}

The overall statistical comparisons between AERONET and GOCART at all 173 sites (Fig. 4) during 2000 to 2007 are shown in Table 3 for monthly and Fig. 6 for annual means of $\tau, \tau_{a}, \omega$, and $\alpha$. The minimum number of days with available AERONET data is 5 for calculating monthly means and 20 

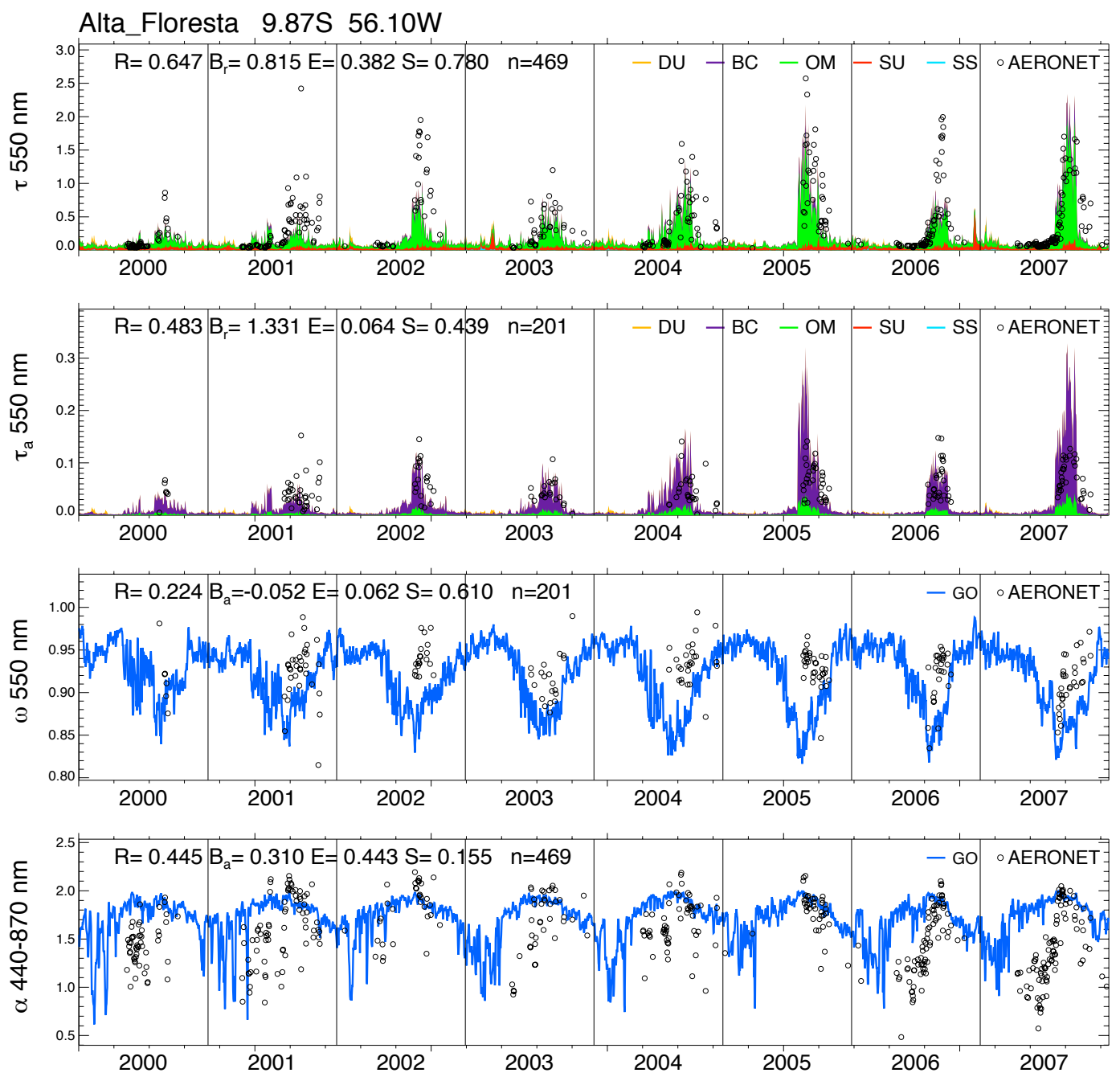

Fig. 5f. Same as Fig. 5a but for Alta Floresta in Brazil.

for annual means. The GOCART results are averaged over the same days for appropriate comparisons. These annual means in Fig. 6 are color-coded for the 7 regions (Fig. 4). Figure 6 shows that about $90 \%$ of model simulated annual averaged $\tau$ agree with AERONET within a factor of two, and on a global basis the modeled $\tau$ is about $8 \%$ lower than the AERONET data. The regions where modeled average $\tau$ is lower than AERONET by $30-40 \%$ are SAM, SAF, and AUS (Table 3), pointing to the likelihood of underestimated biomass burning emissions, as was noted in Fig. 5. The comparison of $\tau_{a}$, on the other hand, is more scattered, as only about $70 \%$ of the points are within a factor of 2 of agreement. There are also recognizable regional differences: modeled $\tau_{a}$ values are lower than AERONET at most sites located in pollution and biomass burning regions except SAM but are higher in dust dominated places (NAF and some sites in ASA), due to the overestimation of dust particle absorption (Fig. 3).
With respect to $\omega$, the modeled values for regions of NAM, EUR, and NAF are mostly confined within a narrow range (Fig. 6), for example, 0.88 to 0.90 for NAF, 0.91 to 0.95 for Europe, and 0.94 to 0.96 for NAM, while the AERONET data for those regions exhibit a much wider spread. Table 3 shows that the largest discrepancies between model and AERONET are in NAF where modeled regional average $\omega$ is 0.03 lower (more absorbing) and in AUS where model is 0.06 higher (less absorbing) than AERONET.

The comparison of $\alpha$ separates the points into two groups, one below the 1:1 line (model being lower) and the other above (model being higher) (Fig. 6). The model calculated $\alpha$ in EUR and NAF are almost exclusively lower than the AERONET observations, as is the majority points in NAM. Overall in these regions, $\alpha$ from the model is $0.2-0.3$ lower than that from AERONET (Table 3). In contrast, modeled $\alpha$ in SAM, SAF, and AUS are almost exclusively higher than AERONET by $0.2-0.3$ on average (Table 3 ). In ASA, the 

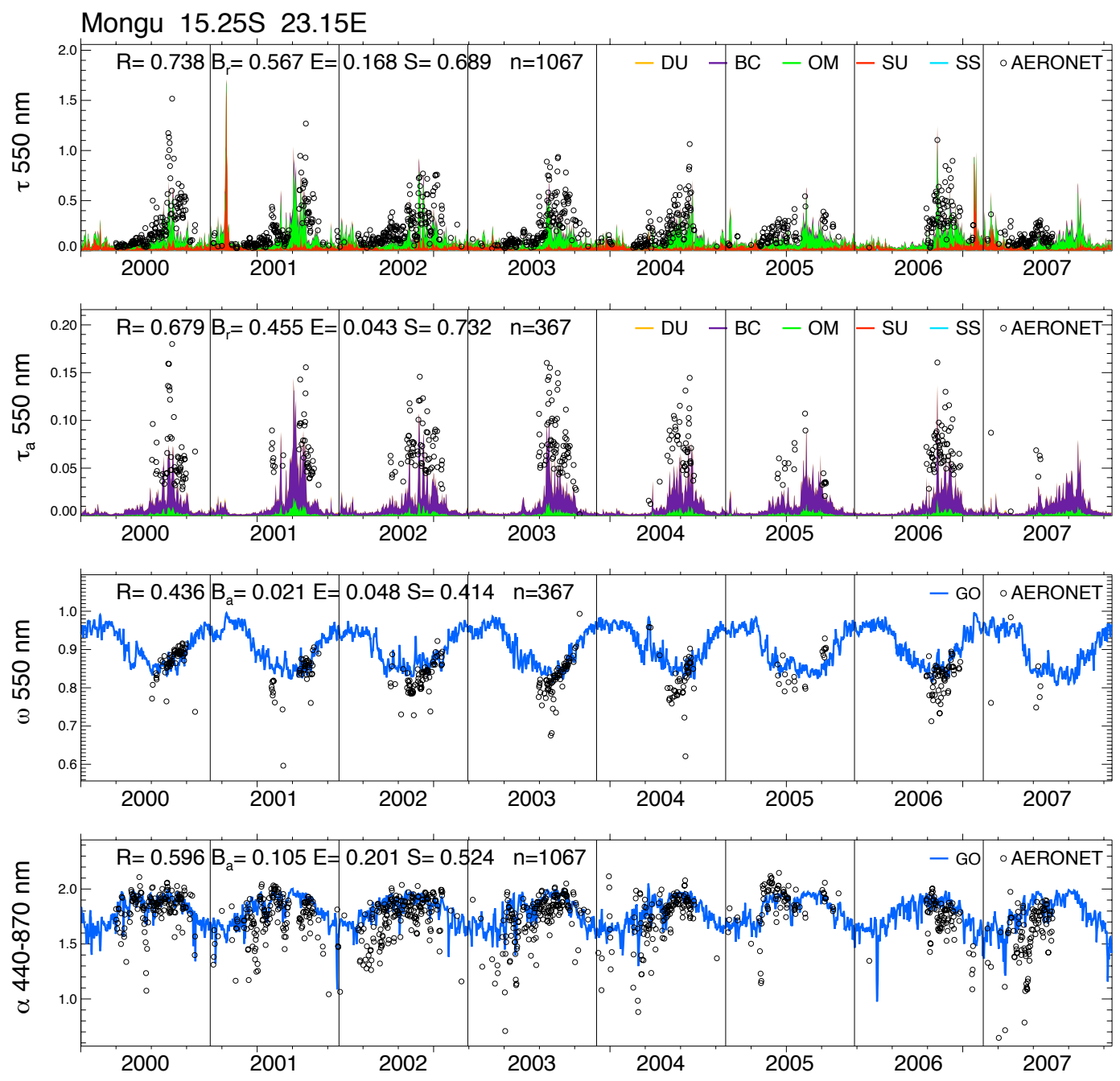

Fig. 5g. Same as Fig. 5a but for Mongu, Zambia.

modeled $\alpha$ are higher at some of the sites but lower at others than that from AERONET; those points where model is higher are dominated by biomass burning aerosols (e.g., Hua Hin, Mukdahan, Pimai in Tailand during burning season) and those where the model is lower are dominated by pollution and/or dust aerosols (e.g., Beijing and SACOL in China, Osaka in Japan, Dalanzadged in Mongolia).

\subsection{Spectral dependence of $\omega$}

We further examine in Fig. 7 the wavelength $(\lambda)$ dependence of $\omega$ in the visible to shortwave infrared (440-1020 nm) spectral range at sites typically regarded as located in pollution, biomass burning, or dust in different regions, similar to that shown in Dubovik et al. (2002). For the four sites in pollution regions (GSFC, Lille, Kanpur, and Beijing, Fig. 7a), both AERONET and GOCART show that in the visible spectral region, $\omega$ is the highest in GSFC among the four sites followed by Lille, and the lowest in Beijing and Kanpur.
However, the spectral dependence from the model is weaker than that from AERONET, and the difference in $\omega$ increases at longer wavelengths. The AERONET retrieval and model simulation display different wavelength dependence of $\omega$ in Beijing and Kanpur: AERONET shows an increase of $\omega$ with $\lambda$ in Kanpur but the model shows a decrease from mid-visible to shortwave infrared. On the other hand, the model exhibits an increase of $\omega$ with wavelength in Beijing, similar to the shape of dust sites (Fig. 7c) but AERONET shows a convex shape with a maximum at $675 \mathrm{~nm}$.

There are large differences in the $\omega-\lambda$ relationship between AERONET and GOCART at the four biomass burning sites (Fig. 7b). AERONET displays a clear separation between forest burning (Bonanza Creek in Alaska and Alta Floresta in Brazil) and savanna/shrub burning (Mongu in Zambia and Lake Argyle in Australia): aerosols at Bonanza Creek and Alta Floresta are much less absorbing and have weaker wavelength dependence than those at Mongu and 

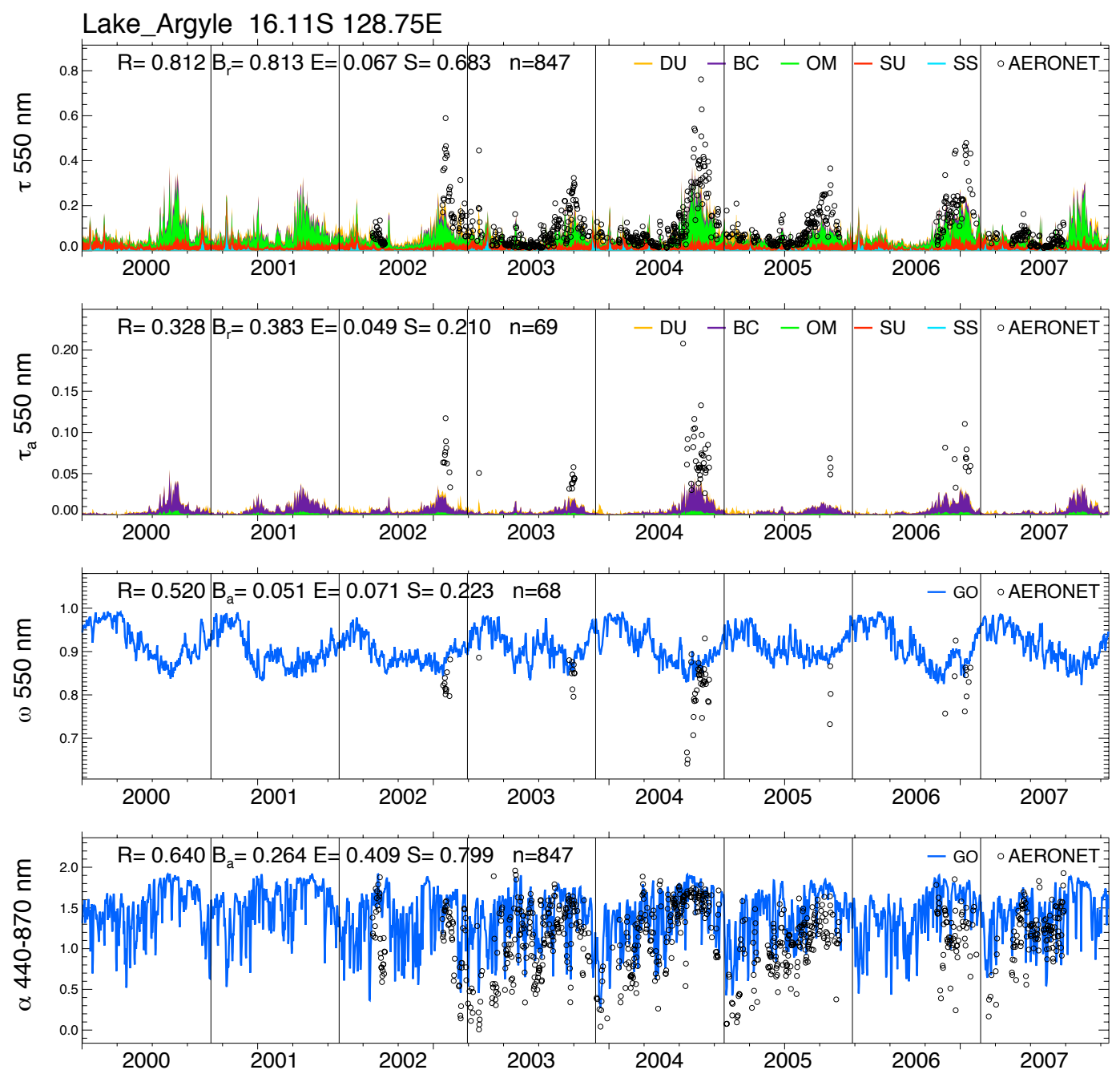

Fig. 5h. Same as Fig. 5a but for Lake Argyle in Australia.

Lake Argyle. The model calculates a much stronger wavelength dependence of $\omega$ than AERONET at all four sites, although the model also shows that at Bonanza Creek aerosol is less absorbing and the wavelength dependence is weaker than at other biomass burning sites because of a higher sulfate fraction at that location, likely from the transport of pollutions from near (North America) and far (Europe and Asia) sources (Chin et al., 2007). The differences between AERONET and GOCART on these biomass burning sites have exposed a deficiency in the model on emission factors in different vegetation types, the particle size distributions, and the optical properties of biomass burning aerosols.

The model and AERONET display similar shapes of spectral dependence of $\omega$ over the four dust sites (Cape Verde and Blida in/near northern Africa, Solar Village in Saudi Arabia, Dalanzadgad in Mongolia) (Fig. 7c), but the modeled $\omega$ is typically 0.02 to 0.03 lower than AERONET and behaves more similarly among the sites. Both model and AERONET show that the $\omega-\lambda$ relationship over Dalazadgad is different from other dust sites, but more so from AERONET data. Model component analysis shows that the sulfate fraction in Dalazadgad is higher than that at other sites, causing less increase of $\omega$ with wavelength.

\subsection{Model evaluation and steps for improvement}

The comparisons discussed above and shown in Fig. 5 to Fig. 7 have clearly revealed the similarities and differences in four key parameters, $\tau, \tau_{a}, \omega$, and $\alpha$ between AERONET and GOCART. A summary of model evaluation is as follows:

1. Among the four parameters, best agreement between AERONET and GOCART are those directly measured by AERONET, namely $\tau$ and $\alpha$, on regional and global scales (Table 3 and Fig. 6). The model has a much lower skill in reproducing the AERONET retrieved quantities of $\omega$ and $\tau_{a}$. 
(a) $\tau 550 \mathrm{~nm}$

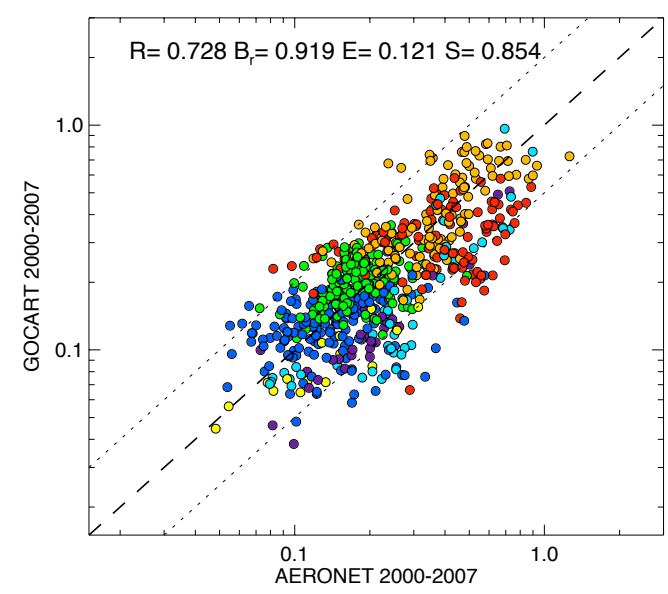

(c) $\omega 550 \mathrm{~nm}$

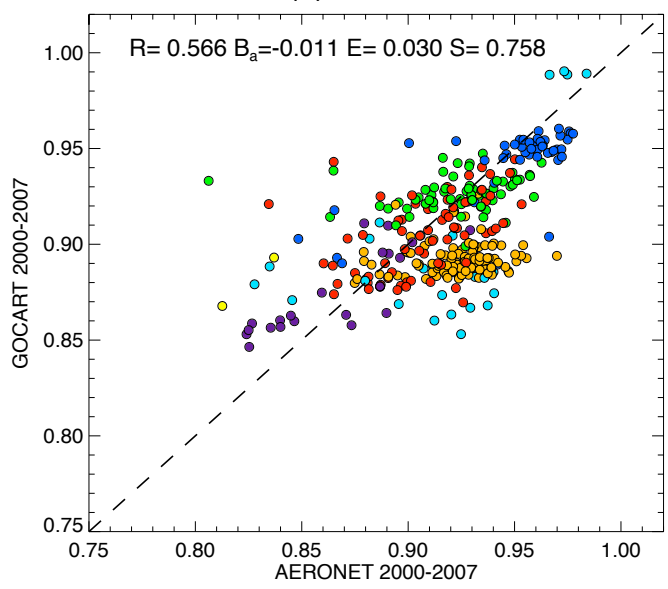

(b) $\tau_{\mathrm{a}} 550 \mathrm{~nm}$

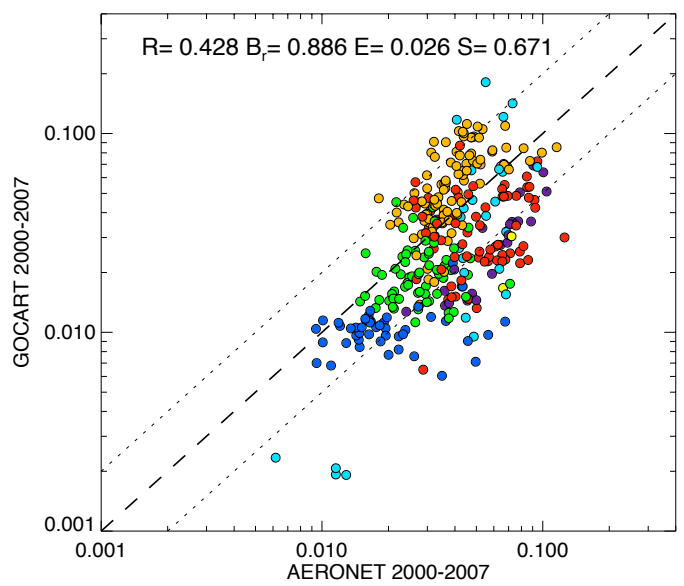

(d) $\alpha 440-870 \mathrm{~nm}$

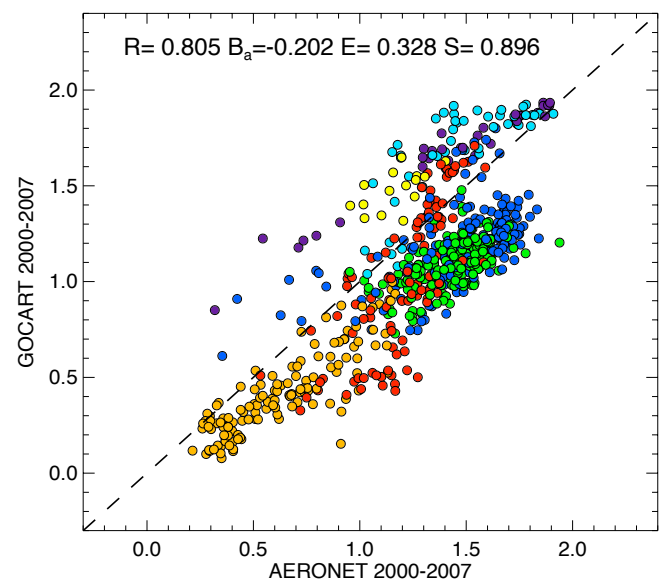

Fig. 6. Overall comparisons of $\tau, \tau_{a}$, and $\omega$ at $550 \mathrm{~nm}$ and $\alpha$ at 440-870 $\mathrm{nm}$ between AERONET and GOCART at all 173 AERONET sites (see Fig. 3) during 2000-2007. Each point represents the annual average of the available AERONET data with a year. Model output is averaged for the same days. Points are color coded according to the regions (see Fig. 3). 1:1 ratio in dashed line and 2:1 in dotted lines on $\tau$ and $\tau_{a}$ panels. Statistical variables on each panel are: $R=$ correlation coefficient, $B_{r}=$ relative mean bias (for $\tau_{\text {and }} \tau_{a}$ ), $B_{a}=$ absolute mean bias (for $\omega$ and $\alpha$ ), $E=$ root-mean-square error, and $S=$ skill score. See text and Fig. 5a caption for explanations.

2. While the systematic bias of model calculated $\tau$ for pollution and dust regions is relatively small, the model systematically underestimate the $\tau$ for biomass burning aerosols by $30-40 \%$ in regions dominated by that type of aerosol, such as in South America, southern Africa, and Australia during the burning seasons. Considering the fact that we have used higher emission factors of carbonaceous aerosols than the commonly suggested values (e.g., Andreae and Merlet, 2001), our still-toolow biomass burning $\tau$ reveals the possibility that the dry mass burned estimates in GFED v2 may be too low, as other studies have also suggested (e.g., Bian et al., 2007).

3. There are clear differences between the model and AERONET on $\alpha$. The modeled $\alpha$ is $0.2-0.3$ too small (or the particles are too large) for pollution because the lognormal distribution sulfate particle size is probably too wide, and yet it is $0.2-0.3$ too large (or the particles are too small) for the biomass burning aerosols because the effective radius of OM particles are probably too small. The $\alpha$ for dust from the model is also about 0.2 to 0.3 smaller than AERONET, suggesting too high a coarse mode fraction of dust.

4. The model estimated $\tau_{a}$ are generally lower than AERONET except in the dust dominated area of NAF. Over pollution-dominated areas the discrepancy indicates that the amount of absorbing aerosol, such as BC, is probably too low in the model. For biomass burning dominated areas, it is likely that the total emission is too low, since the $\tau$ values are also low there. The high bias of modeled dust $\tau_{a}$ is mostly the result of the incorrect optical properties used in the model (i.e. the imaginary 
(a) Pollution Sites
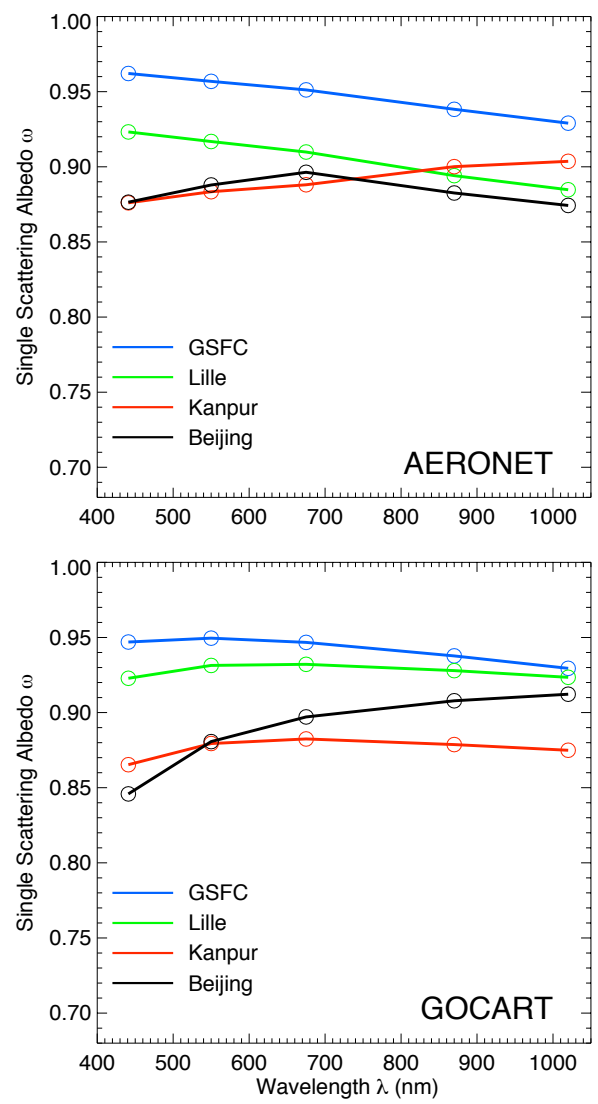

(b) Biomass Burning Sites
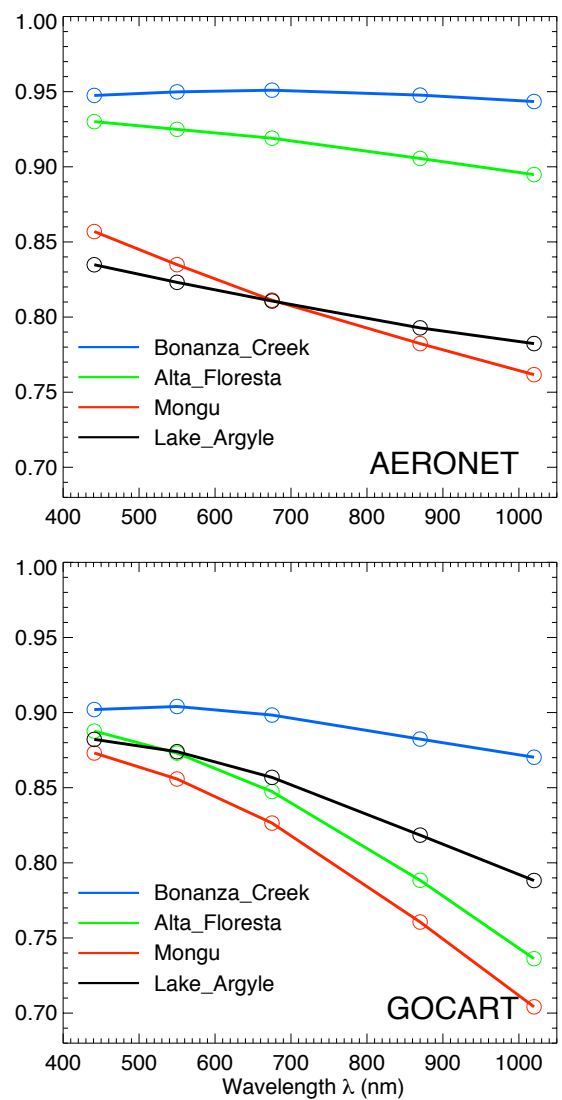

(c) Dust Sites
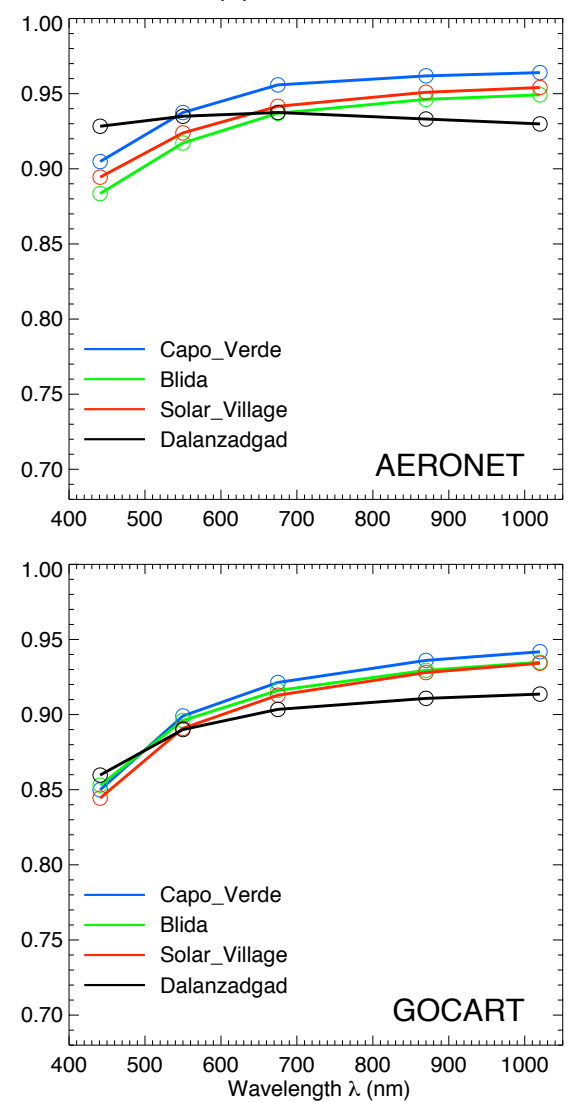

Fig. 7. Spectral dependence of $\omega$ at four sites each located at (a) pollution, (b) biomass burning, and (c) dust regions as shown in the AERONET retrieval (top row) and GOCART model (bottom row). Points are averaged over all available daily data from AERONET retrievals from 2000 to 2007. Site locations are indicated in Fig. 4 and discussed in the text.

part of the refractive index being too high, see Table 2), that is also shown in the values of $\omega$.

5. The $\omega$ at $550 \mathrm{~nm}$ in the model for the dust dominated region of NAF is about 0.03 lower than that from AERONET with a much narrower range between different sites. It is thus possible that the optical property of dust used in model calculation is too absorbing, and the dust property is likely to be different at different locations. From AERONET the $\omega$ of forest biomass burning is much higher (less absorbing) than that from savanna/shrubland burning, reflecting the differences in smoke aerosol composition among different vegetation types. However the model does not take into account of those differences, resulting in more similar values of $\omega$ in different biomass burning regions.

6. The spectral dependence of $\omega$ in different aerosol regimes has shown that the model produces much stronger wavelength dependence for biomass burning aerosols but weaker for pollution aerosols than those from AERONET. This problem is related to the incor- rect size distributions for sulfate and $\mathrm{OM}$ aerosols as discussed in (3).

These comparisons have provided multi-dimensional diagnostics of the shortcomings in the model as well as possible remedies for them. As just mentioned, the dust in the model on average is too absorbing ( $\omega$ at $550 \mathrm{~nm}$ being 0.88 to 0.90 at the dust dominated sites) compared with AERONET, while other studies have reported a wide range of $\omega$ for dust. For example, some studies reported a relatively strong absorption by the Saharan dust with $\omega$ of 0.86 to 0.88 at mid-visible wavelength (Patterson et al., 1977), while others suggested a much weaker absorption of the same dust with a $550 \mathrm{~nm} \omega$ value of about 0.97 (Kaufman et al., 2001), along with still other studies presenting $\omega$ values in between those numbers (Cattral et al., 2003; Bergstrom et al., 2007). Also, retrievals of Saharan dust refractive index based on TOMS or TOMS-AERONET combined observations found a much lower imaginary refractive index (less absorbing) in UV wavelengths than the values archived in the OPAC (Colarco et al., 2002; Sinuyk et al., 2003). For models to incorporate the information from different measurements to 
Table 3. Statistics of AERONET-GOCART comparisons of monthly mean ${ }^{\mathrm{a}} 550 \mathrm{~nm} \tau, \tau_{a}$, and $\omega$ and $440-870 \mathrm{~nm} \alpha$ for seven world regions as well as for all sites from 2000 to 2007. See Fig. 4 for region domains.

\begin{tabular}{lcccc}
\hline Region & \multicolumn{5}{c}{ Statistical quantity } \\
\hline$\tau:$ & $R$ & $B_{r}$ & $E$ & $S$ \\
NAM & 0.509 & 0.907 & 0.098 & 0.543 \\
EUR & 0.440 & 1.120 & 0.091 & 0.718 \\
ASA & 0.459 & 0.759 & 0.245 & 0.594 \\
NAF & 0.650 & 1.135 & 0.198 & 0.825 \\
SAM & 0.769 & 0.638 & 0.198 & 0.866 \\
SAF & 0.851 & 0.613 & 0.114 & 0.729 \\
AUS & 0.837 & 0.675 & 0.071 & 0.585 \\
ALL & 0.685 & 0.959 & 0.154 & 0.834 \\
$\tau a:$ & $R$ & $B_{r}$ & $E$ & $S$ \\
NAM & 0.120 & 0.440 & 0.021 & 0.096 \\
EUR & 0.183 & 0.709 & 0.016 & 0.591 \\
ASA & 0.227 & 0.634 & 0.035 & 0.570 \\
NAF & 0.342 & 1.461 & 0.036 & 0.554 \\
SAM & 0.527 & 0.952 & 0.046 & 0.372 \\
SAF & 0.793 & 0.470 & 0.037 & 0.811 \\
AUS & 0.497 & 0.324 & 0.046 & 0.536 \\
ALL & 0.331 & 0.940 & 0.032 & 0.615 \\
$\omega:$ & $R$ & $B_{a}$ & $E$ & $S$ \\
NAM & 0.455 & -0.005 & 0.036 & 0.560 \\
EUR & 0.189 & 0.002 & 0.030 & 0.372 \\
ASA & 0.533 & -0.004 & 0.030 & 0.721 \\
NAF & 0.140 & -0.032 & 0.044 & 0.181 \\
SAM & 0.498 & -0.022 & 0.045 & 0.746 \\
SAF & 0.677 & 0.010 & 0.027 & 0.698 \\
AUS & 0.531 & 0.058 & 0.063 & 0.540 \\
ALL & 0.468 & -0.014 & 0.037 & 0.679 \\
$\alpha:$ & $R$ & $B_{a}$ & $E$ & $S$ \\
NAM & 0.629 & -0.301 & 0.394 & 0.790 \\
EUR & 0.583 & -0.356 & 0.411 & 0.790 \\
ASA & 0.655 & -0.246 & 0.395 & 0.697 \\
NAF & 0.802 & -0.202 & 0.284 & 0.855 \\
SAM & 0.666 & 0.218 & 0.318 & 0.832 \\
SAF & 0.905 & 0.245 & 0.311 & 0.777 \\
AUS & 0.770 & 0.318 & 0.363 & 0.811 \\
ALL & 0.784 & -0.225 & 0.371 & 0.891 \\
\hline & & & & \\
\hline & & &
\end{tabular}

a Monthly mean is obtained by averaging the available AERONET data in a particular month (minimum 5 days). GOCART monthly mean is calculated for the same days when AERONET data are available.

b $R=$ correlation coefficient, $B_{r}=$ relative mean bias (for $\tau$ and $\tau_{a}$ ), $B_{a}=$ absolute mean bias (for $\omega$ and $\alpha$ ), $E=$ root-mean-square error, $S=$ skill score (see text and Fig. 5a caption for explanation).

calculate the dust absorption, it would require quantitative data of complex refractive indices that cover not only a single or a narrow range of wavelength(s) but also from UV to IR, at least for the solar spectral range. Such optical information should also be obtained from different geographical locations for different mineralogical compositions. A recent study that measures dust refractive index and $\omega$ from 300 to $1000 \mathrm{~nm}$ as a function of iron oxides contents (Lafon et al., 2006), for instance, would be suitable for our purpose albeit the need for extrapolations to longer wavelengths.

$\mathrm{BC}$ absorption in the model is another important area to improve. A recent review (Bond and Bergstrom, 2006) has suggested that the "light absorbing carbon", which is mainly BC, should have a refractive index with higher values for both real and imaginary part (1.85-0.71i) at mid-visible wavelength and higher particle density $\left(1.8 \mathrm{~g} \mathrm{~cm}^{-3}\right)$ than those compiled in the OPAC database (Table 2). Model simulations using the Bond-Bergstrom recommended values resulted in $40 \%$ increase of global averaged $\tau_{a}$ from the simulation using the OPAC optical properties (Stier et al., 2007), implying more than a factor of 2 increase over pollution and biomass burning regions (because dust absorption was not changed in the two simulations). Here, incorporating the Bond-Bergstrom recommended optical properties for BC in our model would likely improve the agreement between model and AERONET on $\tau_{a}$ even though it might worsen that on $\omega$ (Fig. 3 and Table 6). Likewise, the mid-visible optical properties will have to be extrapolated to other wavelengths with larger uncertainties.

Sulfate and OM size distributions in the model should be modified. The comparisons of the $440-870 \mathrm{~nm} \alpha$ at pollution and biomass burning sites (Fig. 6) has made it clear that the wavelength dependence of sulfate is too weak and that of OM is too strong in the model compared to AERONET. It implies too large a size (or too broad a lognormal size distribution) for sulfate particles but too small a size (or too narrow a lognormal size distribution) for OM particles. The AERONET retrieved information on lognormal size distributions at pollution and biomass burning sites can help to refine the size distribution used in the Mie calculations to recalculate the wavelength-dependent mass extinction cross-sections. Although it is the ambient size distributions that AERONET retrieves, the dry size distribution, which is necessary for the Mie calculation, can be inferred from the aerosol water uptake retrieved at the AEROENT sites (Schuster et al., 2009).

Other aspects of model improvements enlightened from this study include considering the distinct biomass burning emission factors for $\mathrm{BC}$ and $\mathrm{OM}$ in different ecosystems, the differences in OM particle size between the combustions and biogenic sources, and biogenic emission amount.

\section{Composition and origin of total and absorbing aerosols}

Keeping in mind the strengths and weaknesses of the model performance from the above evaluation, we present the model simulated global properties and estimated composition and origin as follows. 

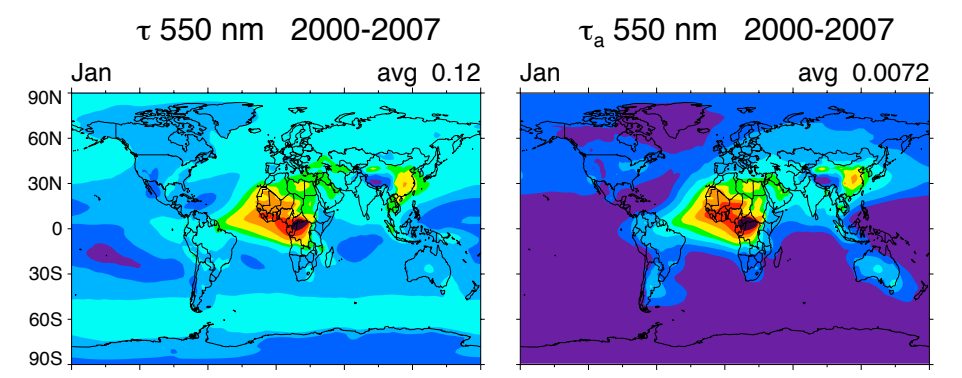

$\omega 550 \mathrm{~nm} \quad 2000-2007$
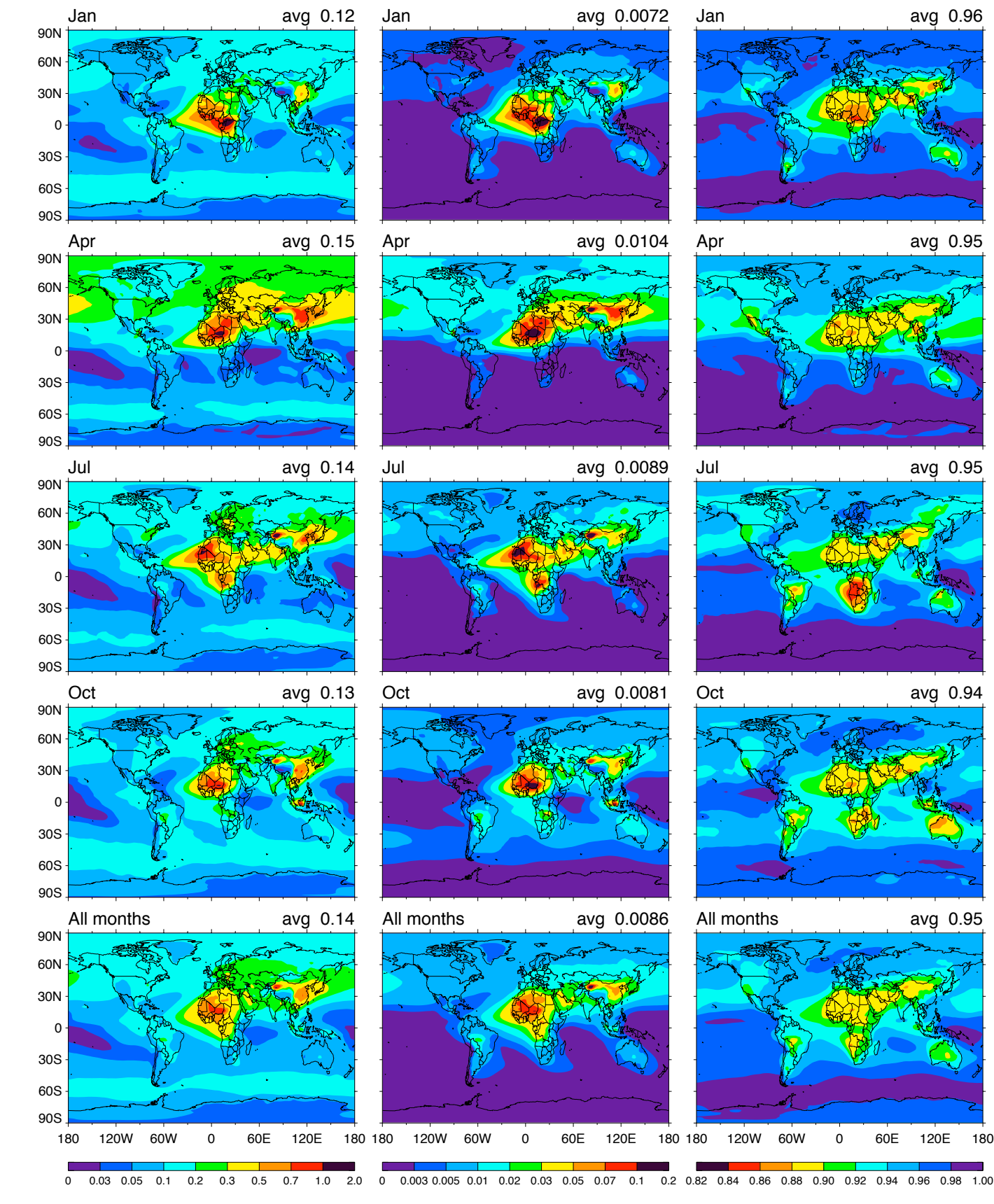

Fig. 8. Global distributions of $\tau$ (left column), $\tau_{a}$ (middle column), and $\omega$ (right column) in January (1st row), April (2nd row), July (3rd row), and October (4th row) averaged over 8-year period from 2000 to 2007 . The time averages of $\tau, \tau_{a}$, and $\omega$ for the entire 8-year period are shown in the last row.

\subsection{Global distributions of $\tau, \tau_{a}$, and $\omega$ and aerosol com- position}

Displayed in Fig. 8 are the model simulated climatology of $\tau, \tau_{a}$, and $\omega$ for January, April, July, October, and the total mean values averaged over the 8-year period from 2000 to 2007. Global averaged $\tau$ and $\tau_{a}$ at $550 \mathrm{~nm}$ are 0.14 and
0.0086 , respectively, for this period. The highest $\tau$ and $\tau_{a}$ are located in regions and seasons with heavy loadings of dust, biomass burning, and pollution, such as northern Africa (mainly dust), northern and eastern China (mainly dust and pollution, respectively), and equatorial/southern hemispheric extra tropical land areas (mainly biomass burning). The lowest $\omega$, or the highest absorbing fraction, is in the biomass 


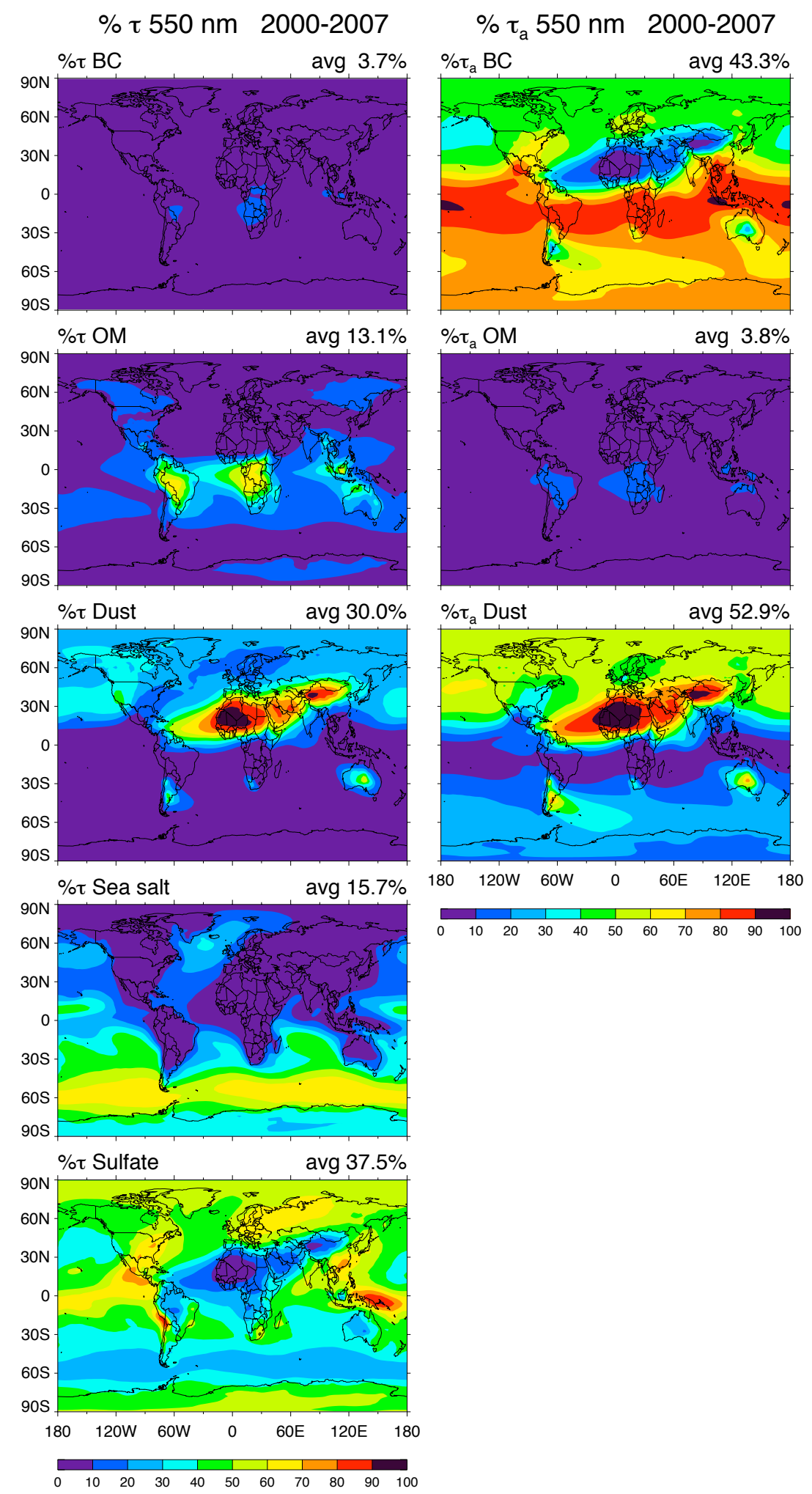

Fig. 9. Left column: Percentage contributions to $550 \mathrm{~nm} \tau$ from BC, OM, dust, sea salt, and sulfate. Right column: same as the left column but for $\tau_{a}$. Sea salt and sulfate are not shown in the right column because of their zero contributions to $\tau_{a}$. 


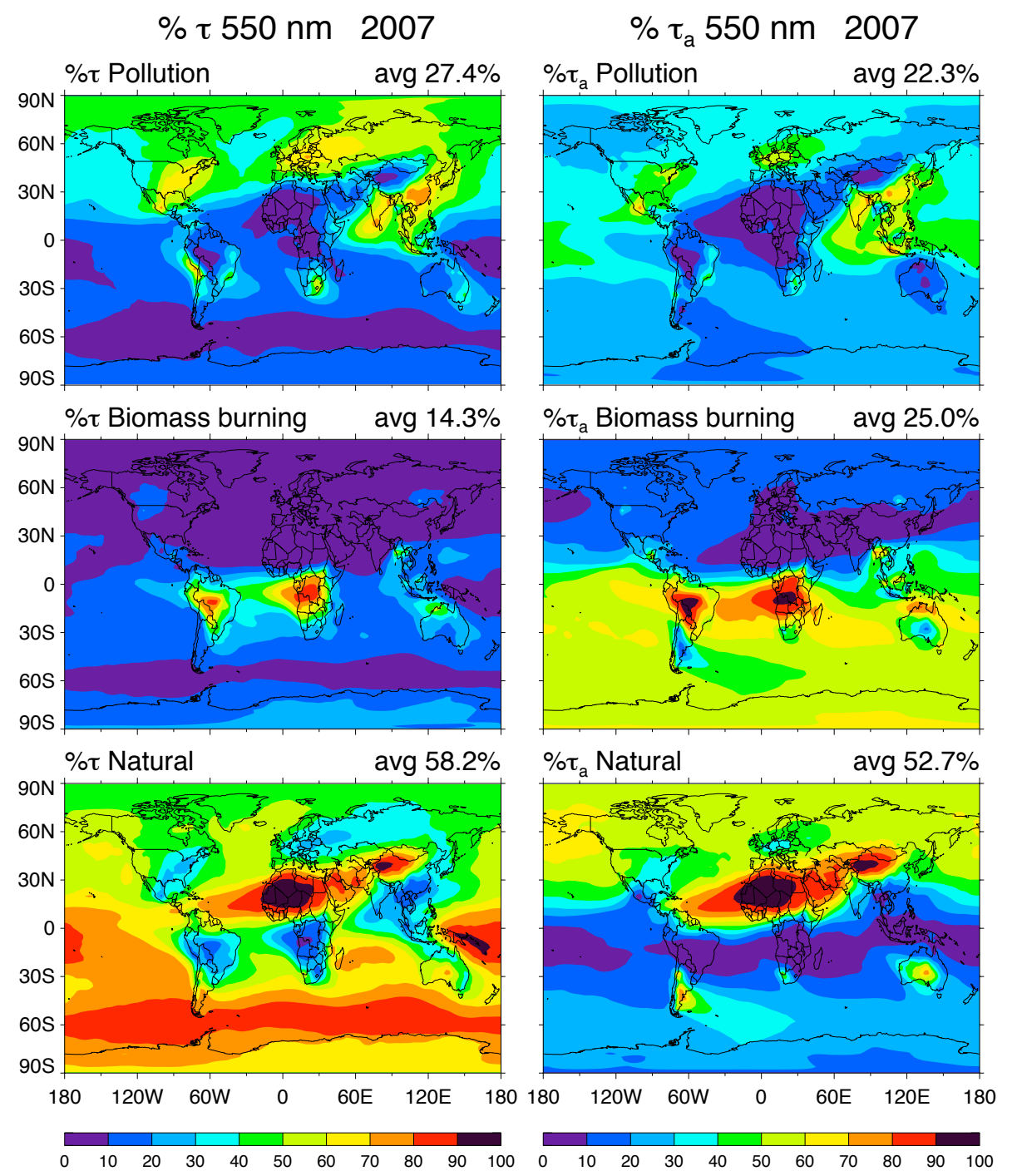

Fig. 10. Percentage contributions to $550 \mathrm{~nm} \tau$ (left column) and $\tau_{a}$ (right column) from pollution (top row), biomass burning (middle row), and natural (bottom row) aerosols in 2007. Natural aerosol including dust, sea salt, biogenic, and volcanic aerosols.

burning areas (tropical northern Africa in January, southern Africa in July), with values ranging from 0.84 to 0.88 . Globally, $\tau$ and $\tau_{a}$ are the lowest in the NH winter (January) and the highest in the $\mathrm{NH}$ spring (April). However there is a large seasonal contrast between $\mathrm{NH}$ and $\mathrm{SH}$. In the $\mathrm{NH}$, the seasonal variation is mostly regulated by the dust and pollution transport while in the SH it is controlled by a strong seasonal cycle of biomass burning, although sea salt also plays a significant role in he southern ocean for $\tau$. Global mean $\omega$ shows little variations in different seasons (0.94 to 0.96) but there are significant differences among regions, mainly controlled by the biomass burning.

The relative contributions of each aerosol component to $\tau$ and $\tau_{a}$ are shown in Fig. 9. Globally, sulfate makes the largest fraction of $\tau$ (37\%), followed by dust (30\%), sea salt (16\%), OM (13\%), and BC (4\%). Although BC is optically thin, it is an important component of aerosol absorption, accounting for $43 \%$ of $\tau_{a}$ while dust contributes to about $53 \%$. Considering that the model may have overestimated $\tau_{a}$ in dust regions but underestimated that in biomass burning regions compared to AERONET (Figs. 5 and 6), we may expect a comparable amount of absorption from dust and $\mathrm{BC}$ if model agreed with AERONET better. The rest, $4 \%$ of $\tau_{a}$, is from OM, which absorbs slightly in the visible wavelength (Fig. 3). Note that these relative contributions are evaluated at the mid-visible wavelength of $550 \mathrm{~nm}$. Because different aerosol species have different spectral variations of specific extinction $\beta$ as well as $\omega$ (e.g., Figs. 3 and 7), these relative percentage numbers will change at different wavelengths.

Comparing with other model calculations, $\tau_{a}$ of $\mathrm{BC}$ from the GOCART model is considerably higher. In the recent multi-model experiments in the Aerosol Comparisons 
Table 4. Aerosol composition, origin, and the relative contribution to $\tau$ and $\tau_{a}$ at $550 \mathrm{~nm}$ for 2007. Numbers in parenthesis are global averages.

\begin{tabular}{|c|c|c|}
\hline Species/origin & $\tau(0.14)$ & $\tau_{a}(0.0090)$ \\
\hline $\mathrm{BC}$ & $3.8 \%$ & $43.9 \%$ \\
\hline Pollution & $1.9 \%$ & $21.8 \%$ \\
\hline Biomass burning & $1.9 \%$ & $22.1 \%$ \\
\hline $\mathrm{OM}$ & $13.3 \%$ & $3.8 \%$ \\
\hline Pollution & $2.0 \%$ & $0.6 \%$ \\
\hline Biomass burning & $9.8 \%$ & $2.9 \%$ \\
\hline Natural $^{\mathrm{a}}$ & $1.5 \%$ & $0.4 \%$ \\
\hline Dust & $30.7 \%$ & $52.3 \%$ \\
\hline Sulfate & $36.1 \%$ & \\
\hline Pollution & $23.6 \%$ & \\
\hline Biomass burning & $2.6 \%$ & \\
\hline Natural $^{\mathrm{a}}$ & $10.0 \%$ & \\
\hline Sea salt & $16.0 \%$ & \\
\hline Total pollution & $27.5 \%$ & $22.3 \%$ \\
\hline Total biomass burning & $14.3 \%$ & $25.0 \%$ \\
\hline Total Natural ${ }^{\mathrm{a}}$ & $58.2 \%$ & $52.7 \%$ \\
\hline
\end{tabular}

${ }^{a}$ Natural OM aerosol including those formed from oxidation of terpene emitted from vegetations. Natural sulfate aerosol including sulfate formed from dimethyl sulfide (emitted from the ocean) and $\mathrm{SO}_{2}$ from volcanic eruptions. These aerosols plus dust and sea salt constitute total natural aerosols.

between Observations and Models (AeroCom) using fixed emissions, the $\tau_{a}$ of $\mathrm{BC}$ at $550 \mathrm{~nm}$ ranges from 0.0011 to 0.0035 among 9 global models with an average value of 0.0019 (Schulz et al., 2006). Similar value (0.0021) is given by the ECHAM model study using the OPAC optical properties for BC (Stier et al., 2007). Our study shows that the $\tau_{a}$ of $\mathrm{BC}$ at $550 \mathrm{~nm}$ is 0.0037 , derived from total $\tau_{a}$ of 0.0086 (Fig. 8, bottom right panel) and the percentage of $\mathrm{BC}$ contribution at $43.3 \%$ (Fig. 9, top right panel). One of the major reasons for this difference is the emission: the total BC emission used in Schulz et al.(2006) and Stier et al. (2007) is $7.6 \mathrm{Tg} \mathrm{yr}^{-1}$ (3.0 $\mathrm{Tg} \mathrm{yr}^{-1}$ biomass burning, $4.6 \mathrm{Tg} \mathrm{yr}^{-1}$ fuel combustion, taken from Dentener et al., 2006), while it is 10.2 $\mathrm{Tg} \mathrm{yr}^{-1}\left(5.0 \mathrm{Tg} \mathrm{yr}^{-1}\right.$ biomass burning, 5.2 $\mathrm{Tg} \mathrm{yr}^{-1}$ fuel combustion, see Table 1) in our study.

\subsection{Origin of total and absorbing aerosol}

We further examine the origin of $\tau$ and $\tau_{a}$ from different sources of dust, biomass burning, and pollution. To do so, we have conducted two additional model simulations, one with biomass burning emissions of $\mathrm{SO}_{2}, \mathrm{BC}$, and $\mathrm{OM}$ turned off, and the other with natural sources only, i.e., excluding anthropogenic and biomass burning emissions. Aerosols from anthropogenic, biomass burning, and natural sources can then be derived from the standard simulation (with all sources) and the simulations with particular sources turned off. These simulations are conducted for 2007 only, when the composition percentages are within $1 \%$ as those in the 8-year climatology (Fig. 9). The budget is listed in Table 4 and also shown in Fig. 10. Here we use the term "pollution" for aerosols from fuel combustions and "natural" for dust, sea salt, volcanic, and biogenic aerosols that include OM produced from terpene (emitted from vegetation) and sulfate from DMS (emitted from ocean) oxidations. We also assume that all dust aerosols are natural even though there is likely some "anthropogenic" dust from land use practices.

Not surprisingly, the highest percentages of $\tau$ for pollution, biomass burning, and natural aerosols are at the vicinities of their strongest source areas: NH mid-latitudes for pollution, tropical/SH subtropical regions for biomass burning, and deserts and remote ocean area for natural aerosols. Volcanic sources control the natural aerosol fraction in the tropical South Pacific (volcanic eruptions from Lopevi and Ambrym in the Vanuatu archipelago and Bagana in the Soloman Islands) and the South Indian Ocean east of Madagascar (eruption of Piton de la Fournaise volcano on Reunion Island), and to a smaller degree in the vicinity of Nicaragua and Costa Rica (degassing volcano Masaya and others). As we have shown in Fig. 9, $\tau_{a}$ consists of mainly two components, dust and BC. Aerosol absorption is dominated by dust in the NH except over the pollution source areas, and by biomass burning aerosols in the SH except over the desert regions in Australia, Argentina, and Chile. Despite the proximity of boreal forest to the Arctic, biomass burning from boreal fire has limited impact on $\tau$ and $\tau_{a}$ in the Arctic (less than $10 \%$ for $\tau$ and $20 \%$ for $\tau_{a}$ on annual average), which is much weaker than the influence of the transport of pollution and dust aerosols. This is in part because the biomass burning is highly seasonal with relatively short duration, in contrast with the constantly available pollution and dust aerosols that are frequently making their way to the Arctic, especially in the winter and spring. Therefore the biomass burning impact to the Arctic is expected to be much larger during the burning season than the annual average. Globally, natural aerosols account for $58 \%$ of $\tau$ and $53 \%$ of $\tau_{a}$, whereas pollution and biomass burning aerosols share the rest. If we assume biomass burning aerosols are mainly from anthropogenic activities, than the total anthropogenic fractions of global $\tau$ and $\tau_{a}$ are $42 \%$ and $47 \%$, respectively.

\section{Conclusions}

We have reported our results from an 8-year (2000-2007) model simulation of atmospheric aerosols that quantifies aerosol absorption and attributes such absorption to aerosol composition and sources from pollution, dust, and biomass burning. The 8-year, global averaged $\tau, \tau_{a}$, and $\omega$ at $550 \mathrm{~nm}$ are estimated at $0.14,0.0086$, and 0.95 , respectively. Sulfate makes the largest fraction of $\tau$ (37\%) globally, followed by dust (30\%), sea salt (16\%), OM (13\%), and BC (4\%). Although BC is optically thin, it is an important 
component of aerosol absorption; it accounts for $43 \%$ of $\tau_{a}$ while dust contributes to about $53 \%$. The rest, $4 \%$ of $\tau_{a}$, is from OM. From a model experiment for 2007 in which the aerosol produced from pollution, biomass burning, and natural sources are "tagged", we have found that the natural aerosols (dust, sea salt, volcanic, and biogenic) account for $58 \%$ of $\tau$ and $53 \%$ of $\tau_{a}$, whereas pollution and biomass burning aerosols share the rest. If we assume biomass burning aerosols come mainly from anthropogenic activities, then the total anthropogenic fractions of global $\tau$ and $\tau_{a}$ are $42 \%$ and $47 \%$, respectively. Given that the model may have overestimated $\tau_{a}$ in dust regions but underestimated that in pollution and biomass burning regions compared to data from the AERONET, we should expect a smaller difference in absorption from dust and anthropogenic aerosols globally. However, these quantities and their relative importance differ significantly with space and time, reflecting the high variability of sources and short lifetimes of aerosols. Also, these relative fractions at $550 \mathrm{~nm}$ will change at other wavelengths since different aerosols have different spectral dependence of mass extinction or absorption cross-sections $\left(\beta\right.$ or $\left.\beta_{a}\right)$.

We have compared the model results of $\tau, \tau_{a}, \omega$, and $\alpha$ with those quantities measured or retrieved from the AERONET at 173 sites worldwide located in pollution, biomass burning, and dust regions. Among the four parameters, those match the best between AERONET and GOCART are the ones directly measured by AERONET, namely $\tau$ and $\alpha$, on regional and global scales. While the systematic bias of model calculated $\tau$ for pollution and dust regions is relatively small, the model usually underestimates the $\tau$ for biomass burning aerosols by 30-40\%. This discrepancy suggests the possibility that the total dry mass burned from the current biomass burning emission dataset is much too low. The modeled size parameter, $\alpha$, is $0.2-0.3$ too low (or the particles are too large) for pollution as well as for dust aerosols but it is $0.2-0.3$ too high (or the particles are too small) for the biomass burning aerosols, indicating errors in the size distributions of those aerosols used in model calculations.

The model has a much lower skill in reproducing the AERONET retrieved quantities of $\omega$ and $\tau_{a}$. Compared with AERONET data, the model estimated $\tau_{a}$ is generally lower except in the dust dominated areas where the model is higher, and the modeled $\omega$ is lower for dust and forest burning areas but higher in savanna/shrubland burning places. These differences may be explained by a combination of several factors, including the incorrect optical properties for dust and carbonaceous aerosols, indiscriminative BC/OM emission factors for different burning vegetation types, and the likelihood of too low biomass burning emissions. The spectral dependence of $\omega$ in different aerosol regimes has shown that the model produces a much stronger wavelength dependence for biomass burning aerosols but a weaker one for pollution aerosols than those from AERONET, a problem that is related mainly to the incorrect size distributions for sulfate and OM aerosols used in the model.
The comparisons between GOCART and AERONET in this study have brought to the forefront the need for the model to incorporate the updated, knowledge based sulfate and OM size distributions, dust absorption properties as a function of iron composition, and BC refractive index. Also, the dry mass burned and trace gas and aerosol released from biomass burning will need to be further refined.

Because of the importance of aerosol absorption in the atmosphere, significant efforts should be undertaken to improve the predictive capability of models with particular respect to such a quantity. The evaluation of current models with satellite or AERONET data is mostly limited in its capacity to the mid-visible wavelength but, as this study has shown, such a comparison is not sufficient enough to evaluate the optical and microphysical properties in the model that are critical for climate studies. As more global model simulations now converge on the $\tau$ values at the mid-visible wavelength (e.g., Kinne et al., 2006, for multiple model studies in AeroCom), which is a result from considerable improvements of models to achieve a better agreement with that quantity from satellite and AERONET measurements, it is now necessary to expand the effort to evaluate the model performance at multi-wavelength and with multi-variables. Such effort will lead to further improved treatment of the chemical, physical, and optical properties in the models that will ultimately be used to assess the aerosol climate impacts of the past and project the climate response to the change of aerosols in the future.

Acknowledgements. The modeling work is supported by NASA Atmospheric Composition Modeling and Analysis Program (ACMAP), Modeling, Analysis and Prediction (MAP), EOS, and Radiation Science Program (RSP). The AERONET site managers and technical personnel are gratefully acknowledged. The NASA Grant Global Environmental Change-hazards and regional impacts (NNX06AF30G) and support from the technical officers Don Anderson and Lucia Tsaoussi are also acknowledged. Constructive comments from the reviewer and from Hongbin Yu are gratefully acknowledged.

Topical Editor F. D'Andrea thanks G. Schuster for his help in evaluating this paper.

\section{References}

Ackerman, A. S., Toon, O. B., Stevens, D. E., Heymsfield, A. J., Ramanathan, V., and Welton, E. J.: Reduction of tropical cloudiness, Science, 288, 1042-1047, 2000.

Andreae, M. O. and Merlet, P.: Emission of trace gases and aerosols from biomass burning, Global Biogeochem. Cycles, 15, 955966, 2001.

Andres, R. J. and Kasgnoc, A. D.: A time-averaged inventory of subaerial volcanic sulfur emissions, J. Geophys. Res., 103(D19), 25251-25262, doi:10.1029/98JD02091, 1998.

Bergstrom, R. W., Pilewskie, P., Russell, P. B., Redemann, J., Bond, T. C., Quinn, P. K., and Sierau, B.: Spectral absorption properties of atmospheric aerosols, Atmos. Chem. Phys., 7, 5937-5943, 2007, http://www.atmos-chem-phys.net/7/5937/2007/. 
Bian, H., Prather, M. J., and Takemura, T.: Tropospheric aerosol impacts on trace-gas budgets through photolysis, J. Geophys. Res., 108, 4242, doi:10.1029/2002JD002743, 2003.

Bian, H., Chin, M., Kawa, S. R., Duncan, B., Arellano, A., and Kasibhatla, P.: Sensitivity of global CO simulations to uncertainties in biomass burning sources, J. Geophys. Res., 112, D23308, doi:10.1029/2006JD008376, 2007.

Bluth, G. J. S., Rose, W. I., Sprod, I. E., and Krueger, A. J.: Stratospheric loading of sulfur from explosive volcanic eruptions, J. Geol., 105, 671-683, 1997.

Bond, T. C., Streets, D. G., Yarber, K. F., Nelson, S. M., Woo, J.H., and Klimont, Z.: A technology-based global inventory of black and organic carbon emissions from combustion, J. Geophys. Res., 109, D14203, doi:10.1029/2003JD003697, 2004.

Bond, T. C. and Bergstrom, R. W.: Light absorption by carbonaceous particles: An investigative review, Aerosol Sci. Technol., 40, 27-67, 2006.

Carn, S. A., Krueger, A. J., Bluth, G. S. J., Schaefer, S. J., Krotkov, N. A., Watson, I. M., and Datta, S.: Volcanic eruption detection by the Total Ozone Mapping Spectrometer (TOMS) instruments: A 22-year record of sulfur dioxide and ash emissions, in: Volcanic Degassing, Special Publication of the Geological Society of London, No. 213, edited by: Oppenheimer, C., Pyle, D. M., and Barclay, J., 177-202, Geological Society, London, UK, 2003.

Carn, S. A., Krueger, A. J., Arellano, S., Krotkov, N. A., and Yang, K.: Daily monitoring of Ecuadorian volcanic degassing from space, J. Volcanol. Geotherm. Res., 176, 141-150, doi:10.1016/j.volgeores.2008.01.029, 2008.

Cattral, C., Carder, K. L., and Gordon, H. R.: Columnar aerosol single-scattering albedo and phase function retrieved from sky radiance over the ocean: Measurements of Saharan dust, J. Geophys. Res., 108(D9), 4287, doi:10.1029/2002JD002497, 2003.

CCSP 2009: Atmospheric Aerosol Properties and Climate Impacts, A Report by the US Climate Change Science Program and the Subcommittee on Global Change Research, edited by: Chin, M., Kahn, R. A., and Schwartz, S. E., National Aeronautics and Space Administration, Washington, D.C., USA, 128 pp, 2009.

Chin, M., Rood, R. B., Lin, S.-J., Müller, J.-F., and Thompson, A. M.: Atmospheric sulfur cycle simulated in the global model GOCART: Model description and global properties, J. Geophys. Res., 105, 24671-24687, 2000.

Chin, M., Ginoux, P., Kinne, S., Torres, O., Holben, B. N., Duncan, B. N., Martin, R. V., Logan, J. A., Higurashi, A., and Nakajima, T.: Tropospheric aerosol optical thickness from the GOCART model and comparisons with satellite and sun photometer measurements, J. Atmos., Sci., 59, 461-483, 2002.

Chin, M., Ginoux, P., Lucchesi, R., Huebert, B., Weber, R., Anderson, T., Masonis, S., Blomquist, B., Bandy, A., and Thornton, D.: A global aerosol model forecast for the ACEAsia field experiment, J. Geophys. Res., 108(D23), 8654, doi:10.1029/2003JD003642, 2003.

Chin, M., Chu, D. A., Levy, R., Remer, L. A., Kaufman, Y. J., Holben, B. N., Eck, T., and Ginoux, P.: Aerosol distribution in the northern hemisphere during ACE-Asia: Results from global model, satellite observations, and sunphotometer measurements, J. Geophy. Res., 109, D23S90, doi:10.1029/2004JD004829, 2004.

Chin, M., Diehl, T., Ginoux, P., and Malm, W.: Intercontinental transport of pollution and dust aerosols: implications for regional air quality, Atmos. Chem. Phys., 7, 5501-5517, 2007,

http://www.atmos-chem-phys.net/7/5501/2007/.

Colarco, P. R., Toon, O. B., Torres, O., and Rasch, F. J.: Determining the UV imaginary part of refractive index of Saharan dust particles from TOMS data and a three dimensional model of dust transport, J. Geophys. Res., 107(D16), 4312, doi:10.1029/2001JD000903, 2002.

Delene, D. J. and Ogren, J. A.: Variability of aerosol optical properties at four North American surface monitoring sites, J. Atmos. Sci., 59, 1135-1150, 2002.

Dentener, F., Kinne, S., Bond, T., Boucher, O., Cofala, J., Generoso, S., Ginoux, P., Gong, S., Hoelzemann, J. J., Ito, A., Marelli, L., Penner, J. E., Putaud, J.-P., Textor, C., Schulz, M., van der Werf, G. R., and Wilson, J.: Emissions of primary aerosol and precursor gases in the years 2000 and 1750 prescribed data-sets for AeroCom, Atmos. Chem. Phys., 6, 4321-4344, 2006, http://www.atmos-chem-phys.net/6/4321/2006/.

Dickerson, R. R., Kondragunta, S., Stenchikov, G., Civerolo, K. L., Doddridge, B. G., and Holben, B. N.: The impact of aerosols on solar ultraviolet radiation and photochemical smog, Science, 278, 827-830, 1997.

Diehl, T., Chin, M., Krotkov, N., Siebert, L., and Carn, S.: A global inventory of subaerial volcanic $\mathrm{SO}_{2}$ emissions from 1979 to 2007, in preparation, 2009.

Duan, F. K., Liu, X. D., He, K. B., Li, Y. W., and Dong, S. P.: Characteristics and source identification of particulate matter in wintertime in Beijing, Water, Air and Soil Pollution, 180, 171183, 2007.

Dubovik, O. and King, M. D.: A flexible inversion algorithm for retrieval of aerosol optical proper-ties from Sun and sky radiance measurements, J. Geophys. Res., 105, 20673-20696, 2000.

Dubovik, O., Smirnov, A., Holben, B. N., King, M. D., Kaufman, Y. J., Eck, T. F., and Slutsker, I.: Accuracy assessments of aerosol optical properties retrieved from AERONET Sun and sky-radiance measurements, J. Geophys. Res., 105, 9791-9806, 2000.

Dubovik, O., Holben, B. N., Eck, T. F., Smirnov, A., Kaufman, Y. J., King, M. D., Tanré, D., and Slutsker, I.: Variability of absorption and optical properties of key aerosol types observed in worldwide locations, J. Atmos. Sci., 59, 590-608, 2002.

Dubovik, O., Sinyuk, A., Lapyonok, T., Holben, B. N., Mishchenko, M., Yang, P., Eck, T. F., Volten, H., Munoz, O., Veihelmann, B., van der Zander, Sorokin, M., and Slutsker, I.: Application of light scattering by spheroids for accounting for particle non-sphericity in remote sensing of desert dust, J. Geophys. Res., 111, D11208, doi:10.1029/2005JD006619d, 2006.

Eck, T., Holben, B., Reid, J., Dubovik, O., Smirnov, A., O’Neill, N., Slutsker, I., and Kinne, S.: Wavelength dependence of the optical depth of biomass burning, urban, and desert dust aerosols, J. Geophys. Res., 104, 31333-31349, 1999.

Eck, T. F., Holben, B. N., Reid, J. S., O’Neill, N. T., Schafer, J. S., Dubovik, O., Smirnov, A., Yama-soe, M. A., and Artaxo, P.: High aerosol optical depth biomass burning events: a comparison of optical properties for different source regions, Geophys. Res. Lett., 30(20), 2035, doi:10.1029/2003GL017861, 2003.

Eck, T. F., Holben, B. N., Reid, J. S., et al.: Spatial and temporal variability of column-integrated aerosol optical properties in the southern Arabian Gulf and United Arab Emirates in summer, J. 
Geophys. Res., 113, D01204, dio:10.1029/2007JD008944, 2008.

Eck, T. F., Holben, B. N., Reid, J. S., et al.: Optical properties of boreal region biomass burning aerosols in central Alaska and seasonal variation of aerosol optical depth at an Arctic coastal site, J. Geophys. Res., 114, D11201, doi:10.1029/2008JD010870, 2009.

Eyring, V., Köhler, H. W., Van Aardenne, J., and Lauer, A.: Emissions from international shipping: 1 . The last 50 years, J. Geophys. Res., 110, D17305, doi:10.1029/2004JD005619, 2005.

Ginoux, P., Chin, M., Tegen, I., Prospero, J., Holben, B., Dubovik, O., and Lin, S.-J.: Sources and distributions of dust aerosols simulated with the GOCART model, J. Geophys. Res., 106, 2022520273, 2001.

Ginoux, P., Prospero, J., Torres, O., and Chin, M.: Long-term simulation of dust distribution with the GOCART model: Correlation with the North Atlantic Oscillation, Environ. Modeling and Software, 19, 113-128, 2004.

Gong, S.: A parameterization of sea-salt aerosol source function for sub- and super-micron particles, Global Biogeochem. Cycles, 17, 1097, doi:10.1029/2003GB002079, 2003.

Hansen, J., Sato, M., and Ruedy, R.: Radiative forcing and climate response, J. Geophys. Res., 102, 6831-6864, 1997.

Hess, M., Köpke, P., and Schult, I.: Optical properties of aerosols and clouds: The software package OPAC, B. Am. Meteorol. Assoc., 79, 831-844, 1998.

Holben, B. N., Eck, T. F., Slutsker, I., et al.: AERONET - A federated instrument network and data archive for aerosol characterization, Remote Sens. Environ., 66, 1-16, 1998.

IPCC: Changes in Atmospheric Constituents and in Radiative Forcing. In: Climate Change 2007: The Physical Science Basis, Contribution of Working Group I to the Fourth Assessment Report of the Intergovermental Panel on Climate Change, edited by: Solomon, S., Qin, D., Manning, M., Marquis, M., Averyt, K., Tignor, M. M. B., Millier Jr., H. L., and Chen, Z., Cambridge University Press, Cambridge, UK, and New York, NY, USA, 2007.

Jacobson, M. Z.: A physically-based treatment of elemental carbon optics: Implications for global direct forcing of aerosols, Geophys. Res. Lett., 27, 217-220, 2000.

Kaufman, Y. J., Tanre, D., Dubovik, O., Karnieli, A., and Remer, L. A.: Absorption of sunlight by dust as inferred from satellite and ground-based remote sensing, Geophys. Res. Lett., 28, 14791483, 2001.

Kaufman, Y. J. and Koren, I.: Smoke and pollution aerosol effect on cloud cover, Science, 313, 655-658, 2006.

Kim, M.-K., Lau, W. K. M., Chin, M., Kim, K.-M., Sud, Y. C., and Walker, G. K.: Atmospheric teleconnection over Eurasia induced by aerosol radiative forcing during boreal spring, J. Climate, 19, 4700-4718, 2006.

Kinne, S., Lohmann, U., Feichter, J., et al.: Monthly averages of aerosol properties: A global comparison among models, satellite data, and AERONET ground data, J. Geophys. Res., 108(D20), 4634, doi:10.1029/2001JD001253, 2003.

Kinne, S., Schulz, M., Textor, C., et al.: An AeroCom initial assessment - optical properties in aerosol component modules of global models, Atmos. Chem. Phys., 6, 1815-1834, 2006, http://www.atmos-chem-phys.net/6/1815/2006/.

Köpke, P., Hess, M., Schult, I., and Shettle, E. P.: Global Aerosol Data Set. MPI Meteorologie Hamburg Report No. 243, 44 pp., 1997.
Krotkov, N. A., Carn, S. A., Krueger, A. J., Bhartia, P. K., and Yang, $\mathrm{K}$.: Band residual difference algorithm for retrieval of $\mathrm{SO}_{2}$ from the AURA Ozone Monitoring Instrument (OMI), IEEE Transactions on Geoscience and Remote Sensing, AURA special issue, 44(5), 1259-1266, doi:10.1109/TGRS.2005.861932, 2006.

Lafon, S., Sokolik, I. N., Rajot, J. L., Caquineau, S., and Gaudichet, A.: Characterization of iron oxides in mineral dust aerosols: Implications for light absorption, J. Geophys. Res., 111, D21207, doi:10.1029/2005JD007016, 2006.

Lau, K.-M. and Kim, K.-M.: Observational relationship between aerosol and Asian monsoon circulation rainfall, Geophys. Res. Lett., 33, L21810, doi:10.1029/2006GL027546, 2006.

Malm, W. C., Sisler, J. F., Huffman, D., Eldred, R. A., and Cahill, T. A.: Spatial and seasonal trends in particle concentration and optical extinction in the United States, J. Geophys. Res., 99, 13471370, 1994.

Malm, W. C., Day, D. E., Kreidenweis, S. M., Collett, J. L., and Lee, T.: Humidity-dependent optical properties of fine particles during the Big Bend Regional Aerosol Visibility Observational Study, J. Geophys. Res., 108(D9), 4279, doi:10.1029/2002JD002998, 2003.

Martin, R. V., Jacob, D. J., Yantosca, R. M., Chin, M., and Ginoux, P.: Global and regional decreases in tropospheric oxidants from photochemical effects of aerosols, J. Geophys. Res., 108(D3), 4097, doi:10.1029/2002JD002622, 2003.

Menon, S., Hansen, J., Nazarenko, L., and Luo, Y.: Climate effects of black carbon aerosols in China and India, Science, 297, 2250 2253, 2002.

Mortlock, A. M. and Van Alstyne, R.: Military, Charter, Unreported Domestic Traffic and General Aviation 1976, 1984, 1992, and 2015 Emissions Scenarios, NASA/CR-1998-207639, 1998.

Patterson, E. M., Gillette, D. A., and Stockton, B. H.: Complex index of refraction between 300 and $700 \mathrm{~nm}$ for Saharan aerosols, J. Geophys. Res., 82, 3153-3160, 1977.

Randerson, J. T., van der Werf, G. R., Giglio, L., Collatz, G. J., and Kasibhatla, P. S.: Global Fire Emissions Database, Version 2 (GFEDv2.1). Data set, available on-line at http: //daac.ornl.gov/ from Oak Ridge National Laboratory Distributed Active Archive Center, Oak Ridge, Tennessee, USA, doi:10.3334/ORNLDAAC/849, 2007.

Reid, J. S., Eck, T. F., Christopher, S. A., Koppmann, R., Dubovik, O., Eleuterio, D. P., Holben, B. N., Reid, E. A., and Zhang, J.: A review of biomass burning emissions part III: intensive optical properties of biomass burning particles, Atmos. Chem. Phys., 5, 827-849, 2005, http://www.atmos-chem-phys.net/5/827/2005/.

Schulz, M., Textor, C., Kinne, S., Balkanski, Y., Bauer, S., Berntsen, T., Berglen, T., Boucher, O., Dentener, F., Guibert, S., Isaksen, I. S. A., Iversen, T., Koch, D., Kirkevåg, A., Liu, X., Montanaro, V., Myhre, G., Penner, J. E., Pitari, G., Reddy, S., Seland, Ø., Stier, P., and Takemura, T.: Radiative forcing by aerosols as derived from the AeroCom present-day and pre-industrial simulations, Atmos. Chem. Phys., 6, 5225-5246, 2006, http://www.atmos-chem-phys.net/6/5225/2006/.

Schuster G. L., Lin, B., and Dubovik, O.: Remote sensing of aerosol water uptake, Geophys. Res. Lett., 36, L03814, doi:10.1029/2008GL036576, 2009.

Schwarz, J. P., Spackman, J. R., Fahey, D. W., et al.: Coatings and their enhancement of black carbon light absorption in the tropical atmosphere, J. Geophys. Res., 113, D03203, 
doi:10.1029/2007JD009042, 2008.

Siebert, L. and Simkin, T.: Volcanoes of the World: an Illustrated Catalog of Holocene Volcanoes and their Eruptions. Smithsonian Institution, Global Volcanism Program Digital Information Series, GVP-3, 2002.

Stier, P., Seinfeld, J. H., Kinne, S., Feichter, J., and Boucher, O.: Impact of nonabsorbing anthropogenic aerosols on clearsky atmospheric absorption, J. Geophys. Res., 111, D18201, dio:10.1029/2006JD007147, 2006.

Stier, P., Seinfeld, J. H., Kinne, S., and Boucher, O.: Aerosol absorption and radiative forcing, Atmos. Chem. Phys., 7, 52375261, 2007, http://www.atmos-chem-phys.net/7/5237/2007/.

Sinyuk, A., Torres, O., and Dubovik, O.: Combined use of satellite and surface observations to infer the imaginary part of refractive index of Saharan dust, Geophys. Res. Lett., 30, 1081, doi:10.1029/2002GL016189, 2003.

Sinyuk, A., Dubovik, O., Holben, B., et al.: Simultaneous retrieval of aerosol and surface properties from a combination of AERONET and satellite, Rem. Sens. Environ., 107, 90-108, doi:10.1016/j.rse.2006.07.0222007, 2007.

Streets, D. G., Bond, T. C., Lee, T., and Jang, C.: On the future of carbonaceous aerosol emissions, J. Geophys. Res., 109, D24212, doi:10.1029/2004JD004902, 2004.
Streets, D. G., Yan, F., Chin, M., Diehl, T., Mahowald, N., Schultz, M., Wild, M., Wu, Y., and Yu, C.: Discerning human and natural signatures in regional aerosol trends, 1980-2006, J. Geophys. Res., 114, D00D18, doi:10.1029/2009GL038984, 2009.

Taylor, K. E.: Summarizing multiple aspects of model performance in a single diagram, J. Geophys. Res., 106, 7183-7192, 2001.

Torres, O., Bhartia, P. K., Sinyuk, A., Welton, E. J., and Holben, B.: Total Ozone Mapping Spectrometer measurements of aerosol absorption from space: Comparison to SAFARI 2000 ground-based observations, J. Geophys. Res., 110, D10S18, doi:10.1029/2004JD004611, 2005.

van der Werf, G. R., Randerson, J. T., Collatz, G. J., and Giglio, L.: Carbon emissions from fires in tropical and subtropical ecosystems, Global Change Biol., 9, 547-562, 2003.

van der Werf, G. R., Randerson, J. T., Giglio, L., Collatz, G. J., Kasibhatla, P. S., and Arellano Jr., A. F.: Interannual variability in global biomass burning emissions from 1997 to 2004, Atmos. Chem. Phys., 6, 3423-3441, 2006, http://www.atmos-chem-phys.net/6/3423/2006/.

Yuan, H., Zhuang, G., Li, J., Wang, Z., and Li, Jie: Mixing of mineral with pollution aerosols in dust season in Beijing: Revealed by source apportionment study, Atmos. Environ., 42, 2141-2157, 2008. 